\title{
Rethinking constructed action
}

\author{
Kearsy Cormier*, Sandra Smith* \& Zed Sevcikova Sehyr ${ }^{\wedge}$
}

*Deafness, Cognition and Language Research Centre, University College London

${ }^{\wedge}$ Laboratory for Language and Cognitive Neuroscience, San Diego State University

\begin{abstract}
We aim to demonstrate the importance of defining linguistic phenomena by using constructed action or CA (i.e. a stretch of discourse that represents one role or combination of roles depicting actions, utterances, thought, attitudes and/or feelings of one or more referents) as an example. The problem is that different assumptions about CA have led to some apparent contradictions about the nature and characteristics of this phenomenon. Based on observations and analyses of British Sign Language narrative data, we outline criteria and recommendations for defining and annotating CA. We show that, in carefully defining the phenomenon in question and providing criteria for its identification, applying these criteria to usage data leads to emergence of particular types of CA. We also show how identifying these types can help resolve some of the apparent contradictions in the literature.
\end{abstract}

Keywords: constructed action; role; role shift; referential shift; quotation; eyegaze; nonmanual signals

\section{Introduction}

Sign languages are known to make use of a representational device where one or more bodily articulators (including the head, face, eyegaze, arms and torso) are used to represent the utterances, thoughts, feelings and/or actions of one or more referents. This phenomenon (or some aspect(s) of it) has been referred to in the signed language literature by a variety of labels; some of the most common include constructed action (e.g., Winston 1992, Metzger 1995, Quinto-Pozos 2007, Quinto-Pozos, Cormier \& Ramsey 2009, Lillo-Martin 2012) and role shift (Lentz 1986, Padden 1986, Quer 2011, Bavin in press). In addition to constructed action and role shift, other terms which seem to refer to this same phenomenon include expressive attribution of expressive elements (Engberg-Pedersen 1993, 1995), reference shift, referential shifting (Engberg-Pedersen 1993, Poulin \& Miller 1995, Emmorey \& Reilly 1998), body classifiers (Supalla 1982, Morgan \& Woll 2003, Supalla 2003), role play (Loew 1984), constructed dialogue, and reported action have also been used. Throughout this paper, by default, we will refer to the phenomenon in question as constructed action (CA). ${ }^{1}$

Terminology used to refer to this phenomenon varies considerably, and it is often unclear if the same assumptions about its nature are being made by different researchers. It is often not even clear whether these terms are used to refer to the same phenomenon, different aspects of the same phenomenon, or perhaps different phenomena altogether. This has led in some cases to inconsistent claims about how $\mathrm{CA}$ is acquired and used by adults, children and learners. 
The aims of this paper are to define and describe constructed action in sign languages, to propose tools for such descriptions and to show that a clear and consistent understanding of CA and its various types can help clarify the apparent contradictions in the sign language literature. We begin by providing an overview of historical approaches to the study of CA followed by a detailed description of types and degrees of CA based on our observations and analyses of the sign language data that we have collected and analysed. We outline criteria and recommendations for defining and annotating CA, illustrated with examples from an annotated dataset of deaf adult signers of British Sign Language (BSL). We attempt to answer two important questions. Firstly, how do we decide and determine what is CA and what is not? Secondly, how do we annotate CA? We begin by describing how CA has been defined in the sign language literature.

\section{Reporting utterances, thoughts and actions of others}

The term constructed action was first coined by Metzger (1995), following work by Tannen (1986, 1989b, a) on constructed dialogue. Metzger (1995) borrowed the term constructed dialogue from Tannen for use with American Sign Language (ASL) for the representation of the dialogue, or words, of a referent, and coined the term constructed action for representing the real or imagined non-verbal aspects of communication (e.g. actions, feelings, emotions) of others.

Metzger (1995) additionally provided a taxonomy of constructed action types in ASL. She claims that constructed action can be represented in different ways: Firstly, 'direct action' is where actions are constructed by the body, face etc. with limited use of lexical signs or classifier constructions ${ }^{2}$, such as the use of GRAB-HIT ${ }^{3}$ and FIST-HITCHIN in (1). Secondly, 'simultaneous direct and indirect action' is where the actions of the body, face etc. co-occur with limited signed narration, as in the sign LOOK-UP in (2) where LOOK-UP is an element of narration co-occurring with nonmanual constructed action. Thirdly, 'indirect action' is where the narrator is primarily describing events with limited co-occurrence of body involvement, such as a slight use of headshake at the end of (3). In direct action, lexical signs are seen as comments of the character being quoted, in contrast with simultaneous direct and indirect action where the use of lexical signs could be understood as a comment by the signer. Metzger claims that simultaneous direct and indirect action thus tends to contain brief supportive descriptions inserted by the narrator. In indirect action, even during a greater amount of signer's narration of events, Metzger argues, signers can still minimally engage the body to enact actions of the referent.

(1)__gaze-down___ gaze to addressee ___ gaze left ___ head shifts left to right GRAB-HIT AWFUL MAN FIST-HIT-CHIN FALL-DOWN-FROM-CHAIR

"And the guy hauls off and hits him, it was terrible. Knocked the guy right out of his chair

(2) _to addressee gaze forward to up left lower lip extended/head tilt/gaze up left MAN CARDS-IN-HAND LOOK-UP "THAT (RAISE HAND) THAT PRO.1"

"So one of the guys at the table says, "Yeah, I'm Baker, that's me." 
Cormier, K., Smith, S., \& Sevcikova, Z. (in press). Rethinking constructed action. Sign Language and Linguistics. (Submitted 4 April 2015. Check for latest version before citing.)

(3) gaze left/eyes close gaze and head move right/head shakes

PUNCH-NOSE (left hand) CL:V (fall back) CL:5 (head-hit-wall)

"and, bam, he's got a fist in his face. Knocked him right out of his chair and into the wall"

Metzger's (1995) conception of constructed action is as an umbrella term for all representations of real vs. imagined actions, utterances and thoughts of referents other than the signer's own, so that constructed dialogue is a subset of constructed action. Many researchers since have attempted to distinguish quotative uses of constructed action (representing dialogue) versus non-quotative uses of constructed action (representing action) (e.g, Pfau \& Quer 2010, Lillo-Martin 2012, Schlenker in press). However, because utterances, emotions, feelings and thoughts can be imagined or inferred by the signer, it is often unclear whether the signer reconstructs them as the utterances, emotions, feelings or thoughts of the character or if the signer is giving a commentary (providing narration) while in the role of that character. For example, in Figure 1, the token of manual CA (CA:swinging-arms) is clearly a representation of action - i.e. the man swinging his arms as he is walking, approaching a campfire. However, the string WANT COOK SOMETHING produced directly afterwards within the same stretch of CA neither represents action nor dialogue (since the man does not say anything). This stretch of CA could be considered to represent the thoughts of the man, as they are imagined/constructed by the signer, or it could be the signer's narration while in character as the man to indicate to the addressee that the man wanted to cook something. Given the unclear status of constructed emotions, feelings or thoughts compared to utterances and actions, we follow Metzger (1995) in considering constructed action to be an umbrella term for both quotative and nonquotative uses, without a need to necessarily distinguish between the two (Cormier, Smith \& Zwets 2013). 


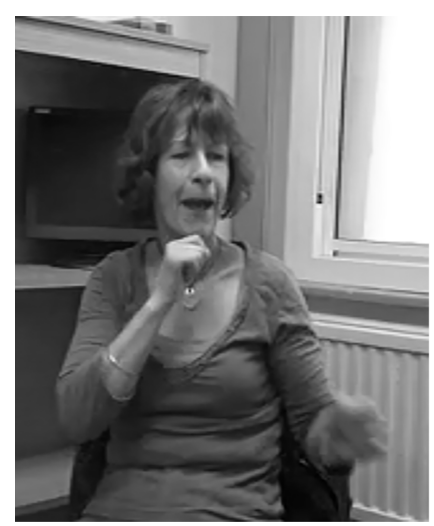

MAN

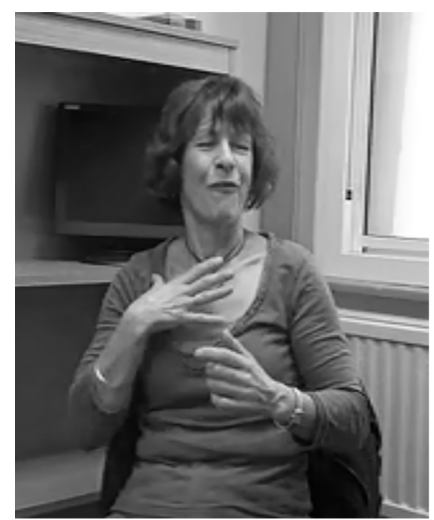

WANT

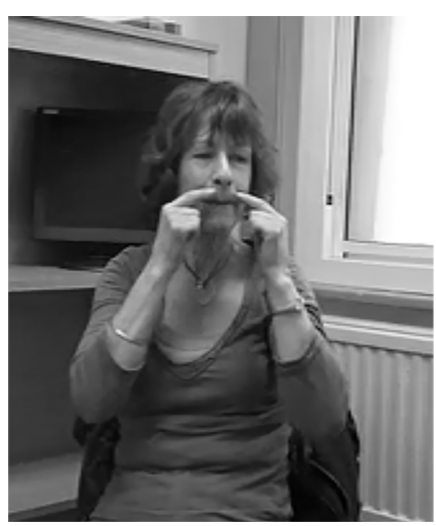

SASS-moustache $\quad<$ CA:man CL-swinging arms

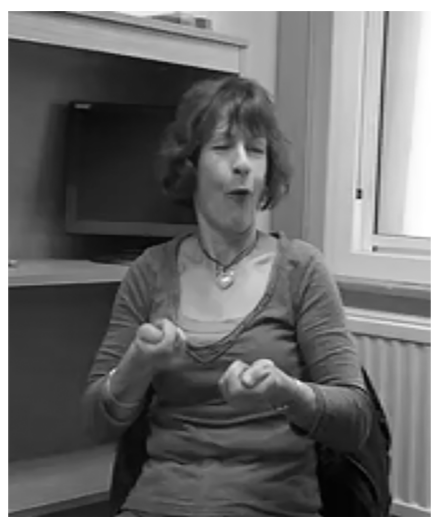

COOK
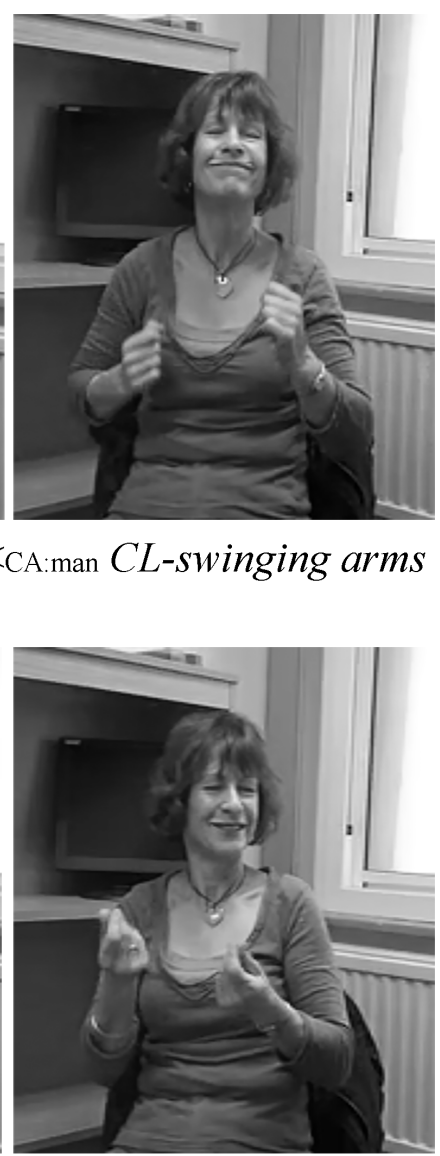

SOMETHING>

Figure 1. MAN SASS:moustache $<_{\text {CA:man }}$ CA:swinging-arms WANT COOK SOMETHING $>$

"The man with the moustache approaches and is like "I want to cook something",

The reproduction or reporting of someone else's actions and particularly utterances has been approached from a formalist perspective by a number of researchers - in these cases, CA has been referred to variably as role shift (e.g., Lee et al. 1997, Quer 2005, Hermann \& Steinbach 2007, Quer 2011, Hermann \& Steinbach 2012, LilloMartin 2012, Schlenker in press), point of view predicate (Lillo-Martin 1995), referential shift (Poulin 1994, Poulin \& Miller 1995), and role prominence marker (Kegl 1995). Such analyses concern themselves primarily with referential language within quotative uses of CA, e.g., the use of personal reference pronouns (first vs. third) or what happens with indexicals when a shift occurs, and interpretation of pronouns and indexicals in relation to the situation of the quoted context. ${ }^{4}$

For example, in their description of functions of referential shift in direct discourse in Quebec Sign Language (Langue des signes québécoise, LSQ), Poulin \& Miller (1995) adopt the term referential shift to account for structures in which the signer uses a first person pronoun to refer to a third person referent. In direct discourse, i.e. reporting utterances or actions, states or thoughts, they distinguish between two forms utterances can take to signal a change in viewpoint on the part of the signer: an 'unmarked form' and 'referential shift'- essentially, the non-use of CA versus the use of CA. In the unmarked form, they claim that the signer can use facial expression, for example, to express judgment, criticism, emotion on the part of the signer rather than the discourse actor (this they argue represents a neutral point of view, "not involved"). 
On the other hand, they claim that the facial expression realised in referential shift (marked form) expresses the internal feelings of the discourse actor who the signer identifies with (this they argue represents an internal point of view, "involved"). Furthermore, they argue that an involved comment that is directly associated with the content of the event is acceptable when uttered during referential shift but a neutral comment is not, and a neutral comment is only acceptable when uttered during the unmarked form - i.e. outside of referential shift.

Engberg-Pedersen (1993, 1995), adopting a broadly cognitive/functional rather than formalist approach, expanded on the phenomenon of reporting and provided an analysis of how point of view can be expressed by shifting reference. EngbergPedersen observed that expressing a specific point of view in Danish Sign Language is realised through the use of reference shifting devices, so called 'shifters'. She proposed that a signer can express a specific point of view by shifting any/all of three aspects of utterances: 'shifted reference', 'shifted attribution of expressive elements' and 'shifted locus'. 'Shifted reference' is limited to direct quotes and reported speech. The narrator signs as if she were the character (including shifting pronouns and other indexical signs); this appears similar to what Metzger's (1995) notion of constructed dialogue and Lillo-Martin's (2012) notion of quotative constructed action. A related phenomenon for Engberg-Pedersen, 'shifted locus', involves changes in the referential use of signing space so that particular locations in space can be associated with different referents. Finally, via 'shifted attribution of expressive elements,' the signer provides certain expressive elements including lexical/manual exclamations or swearing/curses, or non-manual elements expressing his/her attitude about something by facial expression or body posture, e.g. despair, enthusiasm, etc. Such elements can be those of the signer or attributed to the quoted person. If shifted expressive elements occur in reported (direct) speech, they are understood as expressing the quoted person's attitude. If articulated outside reported speech they would be understood as expressing the signer's own attitude. 'Shifted attribution of expressive elements' contributes to the impression that the events of the narrative are presented through the psyche of one of the characters and appears to be the equivalent of Metzger's constructed action. Engberg-Pedersen $(1993,1995)$ explains that a given token of CA may include one, two or all three of the above elements. These elements have been adopted for the purposes of identification of CA in other studies (e.g., de Beuzeville et al., 2009 - see $\$ 2.3$ below). The assumed relationships between the types of CA proposed by Metzger (1995), Engberg-Pedersen (1993), Lillo-Martin (2012) and Schlenker (in press) are shown in Table $1 .^{5}$ These are the only scholars we are aware of who distinguish between types of constructed action or role shift. 
Cormier, K., Smith, S., \& Sevcikova, Z. (in press). Rethinking constructed action. Sign Language and Linguistics. (Submitted 4 April 2015. Check for latest version before citing.)

\begin{tabular}{|l|l|l|l|l|}
\hline $\begin{array}{l}\text { Metzger } \\
(1995)\end{array}$ & $\begin{array}{l}\text { Constructed } \\
\text { dialogue }\end{array}$ & Direct action & $\begin{array}{l}\text { Simultaneous } \\
\text { direct and } \\
\text { indirect action }\end{array}$ & Indirect action \\
\hline $\begin{array}{l}\text { Engberg- } \\
\text { Pedersen } \\
(1993)\end{array}$ & $\begin{array}{l}\text { Shifted } \\
\text { reference; } \\
\text { Shifted } \\
\text { attribution of } \\
\text { expressive } \\
\text { elements }\end{array}$ & $\begin{array}{l}\text { Shifted } \\
\text { attribution of } \\
\text { expressive } \\
\text { elements }\end{array}$ & $\begin{array}{l}\text { Shifted attribution } \\
\text { of expressive } \\
\text { elements }\end{array}$ & $\begin{array}{l}\text { Shifted } \\
\text { attribution of } \\
\text { expressive } \\
\text { elements }\end{array}$ \\
\hline $\begin{array}{l}\text { Lillo- } \\
\text { Martin } \\
\text { (2012) }\end{array}$ & $\begin{array}{l}\text { Quotative } \\
\text { role shift }\end{array}$ & $\begin{array}{l}\text { Non-quotative } \\
\text { role shift }\end{array}$ & $\begin{array}{l}\text { Non-quotative } \\
\text { role shift }\end{array}$ & $\begin{array}{l}\text { Non-quotative } \\
\text { role shift }\end{array}$ \\
\hline $\begin{array}{l}\text { Schlenker } \\
\text { (in press) }\end{array}$ & $\begin{array}{l}\text { Attitude role } \\
\text { shift }\end{array}$ & $\begin{array}{l}\text { Action role } \\
\text { shift }\end{array}$ & Action role shift & Action role shift \\
\hline
\end{tabular}

\subsection{Articulators used to mark constructed action}

In addition to different subtypes of $\mathrm{CA}$ in terms of levels of narration and representation of action, researchers have different conceptions of the articulators that are used to mark it. Most authors seem to agree that a change or a break in eyegaze is the main and obligatory parameter of CA in sign languages (Loew 1984, Padden 1986, Kegl 1995, Reilly 2000). According to Padden (1986), both eyegaze and facial expression determine role shifting but body position change is optional. Specifically, Padden referred to 'two-character role shift' as 'contrasting role shift' which involves perceptible body shift to one side or the other, versus 'one-character role shift', which involves changes in facial configuration and eye gaze but not body position. In 'contrasting role shift', Padden argues, the signer shifts into the character's role, marked by a body shift to the signer's right, followed by a body shift to the left marking the role of another character.

For Metzger (1995) and Pyers \& Senghas (2007), it is the facial expression, head and body position change (such as orientation of the shoulders, the head etc.) or optional break in eyegaze that determine when CA occurs. Zimmer (1989) suggested that body movements, such as directional or lateral body shifting of the entire torso could be interpreted as types of devices that signal or support CA. In her study, such body movements were used to indicate reported speech and were more pronounced in formal registers in contrast with only head movements in informal talk that were used to mark different speakers.

Casey (2003) argues that CA ("role shift") can be used to show action between two participants, so one person is represented by the signer within the 'role shift' while the other person is indicated by the endpoint of the movement of the verb, the spatial placement of the verb, or by body position in space. Although clear criteria are not provided, Casey's use of the term 'role shift' seems to refer to the way the signer moves their body to a location to establish a referent then switches between them to indicate two referents in opposing locations. For example, Casey observed that in order to describe a scene in which one actor put a hat on the other, the signer moved her body to the left to refer to the agent and to the right to refer to the recipient. When the signer was 'in' the recipient space, she produced a 'put on' gesture indicating that the hat was placed on the recipient's head. She gives an example where a child was 
turning her body to the side to take on the perspective of a mother when describing a mother scolding her children.

However, some have noted that these lateral torso shifts are only one possible way of marking referents in constructed dialogue, particularly when two or more referents are involved (Zimmer 1989, Padden 1990). Similarly, Janzen (2004) found that torso shifts only occurred in his data when they represented the stance of the referent (i.e. the body position of the referent) rather than as markers of constructed action on their own. Quinto-Pozos \& Mehta (2010) also noted that use of torso shift was optional in constructed action, particularly in certain registers.

In addition to the use of CA for representing multiple roles sequentially (e.g. one referent and then another), Dudis (2004) suggested that it is possible for signers to use real-space blends to represent a number of referents simultaneously using constructed action via body partitioning where different articulators (e.g. hands, face, body, head) function as 'partitionable zones' representing different referents (i.e. different roles). ${ }^{6}$ These zones (especially each of the hands, the face and the mouth) can each represent different types of information, all of which contribute to the real-space blend but in different ways. The hands are particularly partitionable such that they may be used during the blend to produce classifier constructions or other lexical signs simultaneously while still maintaining the blend.

\subsection{Degrees of constructed action}

In addition to considerations of active articulators, it appears that some researchers may conceive of CA as only existing in its most overt form. However, some have noted the fact that CA can vary in degree. For example, Lentz (1986) and QuintoPozos \& Mehta (2010) consider degree of CA in relation to the intensity with which it is articulated. Lentz (1986) follows Padden's (1986) definition of CA ("role shift") and describes varying degrees of role shifting (i.e. from minimal to maximum) depending on how fully the signer assumes the roles of the characters discussed. Lentz describes how signers take on the manner or expression of another person when describing their appearance, and how the role is assumed more fully when telling what a character thought, said or did. Similarly, Quinto-Pozos \& Mehta (2010) define three degrees of CA: slight, moderate, and exaggerated - where the degree is based on the intensity of the nonmanual articulators that are used to represent the referent(s) involved.

\subsection{Conflicting views on eyegaze as marking $\mathrm{CA}$ versus agreement}

Non-manual articulators can of course function in ways other than just depicting the actions or feelings of the referent. There are several reasons why a signer might break or redirect eye contact, including as prosodic or conversational marker (e.g. to hold the floor) or as a topic marker (Bahan \& Supalla 1995, Coates \& Sutton-Spence 2001, Kooij, Emmerick \& Crasborn 2004, Hansen \& Hessman 2007), although distinguishing these various uses can be challenging. But it is important for researchers to be clear about their use of terms such as CA and role shift and likewise to consider $\mathrm{CA}$ as a possible explanation when the phenomenon being studied could fit the description. For example, de Beuzeville et al. (2009) found that in their analysis of data from the Auslan (Australian Sign Language) Corpus, CA significantly favoured co-occurrence of spatial modification (also known as verb agreement in the sign language literature). De Beuzeville et al. defined CA following Engberg- 
Pedersen's (1993) notions of shifted attribution of expressive elements, shifted reference, and/or shifts of the body, head or gaze (described above). Although de Beuzeville et al.'s findings were not specifically about eyegaze, they discuss eyegaze as a possible marker of CA. Separately, Neidle et al. (including Bahan 1996, Lee et al. 1997, Neidle et al. 2000), Thompson (2006), and Thompson et al. (2006, 2009) argued for eyegaze as a grammatical non-manual marker of verb agreement in ASL. It seems plausible that the use of eyegaze described by Neidle et al. and Thompson et al. could also (or alternatively) be explained by use of CA via eyegaze, particularly given crosslinguistic similarities in the use of CA across sign languages (Quinto-Pozos, Cormier \& Ramsey 2009, Lillo-Martin 2012). However, neither Neidle et al. nor Thompson et al. consider CA as a possible explanation for the patterns they describe. Thus it is very difficult to know if these studies on Auslan and ASL are describing the same or different phenomena. We will return to this issue in $\S 6$.

More recently, there has been another study on eyegaze and agreement conducted by Hosemann (2011) on German Sign Language. Unlike the ASL studies, Hosemann did recognise the need to distinguish between eyegaze as used for agreement versus eyegaze as used for constructed action or role shift: "gaze due to role shift can likewise be directed to the left or right of the signer and might show the same cursor positions as eye gaze agreeing with the object location. However, eyegaze due to role shift differs from eyegaze due to agreement, as it is (i) often accompanied by a body shift, and (ii) spreads over the entire phrase rather than only over a single verb (cf. Lillo-Martin 1995, Hermann \& Steinbach 2007, 2012). These criteria were used to differentiate between eyegaze due to role shift and gaze towards the object or locative" (pg. 85). This is problematic for a few reasons. Firstly, Hosemann's claim that role shift is 'often accompanied by body shift' is not enough to determine the presence of role shift. As noted above in §Error! Reference source not found., there are various claims in the literature about what nonmanual markers are most crucial for role shift, body shift is widely considered optional, and the optionality of body shift is even noted by Hosemann herself earlier in the same paper: "Furthermore, eyegaze shift (i.e. gazing away from the addressee) is the crucial signal to indicate role shift. Most often, it is claimed that role shift is marked by body shift and head tilt, but Herrmann \& Steinbach (2007: 162, to appear [2012]) have recently shown that only eyegaze is obligatory for marking role shift, whereas body lean and head tilts are optional markers" (p. 77). Secondly, we call into question the use of presence versus lack of eyegaze spread as a rubric to determine role shift versus "agreement", respectively. Which 'entire phrase' would the eyegaze need to spread over in order to be considered a marker of role shift? Presumably this refers to the verb phrase. However, in many sign languages, verb phrases (indeed entire clauses) often consist of only a single verb (Sandler \& Lillo-Martin 2006, Johnston et al. 2007, McKee et al. 2011). It is not clear from Hosemann (2011) if her data included overt arguments or not. In any case, when annotating CA in sign language datasets generally, given known patterns of argument drop, eyegaze spread across the verb phrase would not be a useful way of identifying eyegaze for the purposes of $\mathrm{CA} /$ role shift. We suggest that a better system is to use the Dependency Principle described below in $§ 3.3$.

\subsection{Conflicting views on acquisition of $\mathrm{CA}$}

In addition to conflicting claims about eyegaze and $\mathrm{CA}$, there have been conflicting views on the acquisition of $\mathrm{CA}$ in the sign language literature. The use of enactment in early communication has been reported in early signing (e.g., Loew 1984) and in 
early gestures by hearing children (e.g., McNeill 1992) around 2 years of age. It has been reported that deaf children acquiring sign language natively begin to use elements of constructed action in their signed narratives relatively early, before age 3 (Supalla 1982, Loew 1984, Schick 1987, Reilly 2000, Slobin et al. 2003) but this progresses slowly. It has been argued that even by age 12, children still struggle with various discourse and pragmatic functions of CA (Slobin et al. 2003). But it is unclear which aspects of CA are those that appear early in signing and which are the ones that are acquired by children much later.

Some have claimed that some elements of constructed action such as the facial expressions and other non-manual elements to enact other referents are acquired by deaf children early. For instance, Loew (1984) studied the development of 'role play' and reference in the signing of primarily one deaf child (Jane) between ages 3;1 and 4;9 acquiring ASL from deaf parents. Loew found that at the earliest period, even though the reference of the role play is unclear, even at the earliest stage at age 3;1$3 ; 4$, Jane uses mimetic non-manual features to mark roles separately from narrative material.

Likewise, Casey (2003) examined the 'role-shift like' devices that ASL signers employ in order to take on the role of another person to quote speech or to portray actions from another person's perspective, including spatial signals which indicate changes in role such as changes in body or head position. Casey argues that such productions are acquired by deaf native signing children relatively early, before age 3 , are easily innovated, and do not have to be learned.

Others have noted the difficulty with which deaf children acquire elements of constructed action. Emmorey \& Reilly (1998) argued that deaf children aged 3 to 7 years appear to master manual lexical signs before the non-manual behaviours such as the use of facial expression for linguistic purposes such as signalling role shift. This could be seen as at odds with what Loew (1984) and Casey (2003) found.

Many researchers have reported that acquisition of CA or role shift is protracted and slow in hearing adults learning sign language as a second language (e.g., Lentz 1986, McKee \& McKee 1992, Metzger 1995, Quinto-Pozos 2005, Goswell 2011). This seems to contradict notions that some elements of CA are acquired by both hearing and deaf children early and do not have to be learned. The reasons for these contradictions appear to be due to inconsistent assumptions and/or unclear conceptions about what CA is and what it is not. For example, some may be making claims about the use of facial expression or eyegaze for representation of action or utterances, while others may be focusing instead on the use of body shift instead. Some claims may be about "stronger", more overt uses of CA, while others may be about "weaker", subtler uses of CA.

\subsection{Aims of this paper}

In this paper, provide some criteria for identification of CA and also for determining degrees of CA, which have been developed during annotation of elicited data from adult and child signers of BSL. We show how, by applying these criteria to previous studies on CA, some of the apparent contradictions about CA (e.g. ease or difficulty) could be resolved. We also consider how this can help resolve contradictions arising from studies where $\mathrm{CA}$ is not even the primary phenomenon being under investigation. 


\section{Annotation of constructed action and role}

\subsection{Data source}

The proposal and recommendations made in this paper are based on analyses of data collected as part of a longitudinal project that investigated the effect of age of acquisition of BSL/extent of experience with BSL on mastery of constructed action (CA) and entity classifier constructions (CL). The data were collected using a set of cartoon clips and short animations selected or designed specifically to elicit and compare the use of $\mathrm{CA}$ and $\mathrm{CL}$ across deaf signers with different ages of BSL acquisition (adults, children, native, non-native) and to find out how these constructions develop in children over time (ages 6 to 10). Initial findings from the adult data and the 6-year-old child data have been reported in Cormier, Smith \& Sevcikova (2013) and Cormier, Smith \& Zwets (2013). The proposals put forth in this paper are based on our observations and analyses of the data collected. The supporting examples in this paper are based on data collected from adult deaf signers with various ages of BSL acquisition.

\subsection{CA and Role tiers}

Signed language narratives were collected using short cartoon clips (excerpts from the Pink Panther cartoon Keep Our Forests Pink, and the Wallace \& Gromit film The Wrong Trousers) and tokens of constructed action were annotated and analysed using the multimedia annotation tool ELAN (http://www.lat-mpi.eu/tools/elan). No signing occurred in the cartoon clips and animations. The remainder of this paper therefore will focus primarily on non-quotative constructed action, since clearly quotative uses of CA were not possible with these data. (However, we briefly mention implications for work on quotative $\mathrm{CA}$ in $\$ 3.5 .3$.)

The elicited narrative data were coded for constructed action and the role that the signer was representing within the narrative via constructed action (e.g. Pink Panther or the dog) was also identified. Signed productions were also coded for lexical signs and classifier constructions on separate tiers. All data were coded by Deaf, fluent signers of BSL, who are native signers of BSL or another sign language. Annotations were checked by a hearing fluent signer of BSL and a Deaf native signer of BSL to ensure consistency and adherence to the coding guidelines outlined below.

Multiple tiers were created in ELAN to account for various aspects of discourse and included 'gloss' tiers for identifying primarily lexical material, 'role' tiers for identifying the signer's narrative perspective (role), CA tiers to identify instances of $\mathrm{CA}$, and 'classifier' tiers for identifying whole entity classifier constructions among others.

The following subsections describe the coding procedure for the two main sets of tiers of interest here, CA and Role, in more detail. 'Role' was coded in the 'primary role' (Role 1) tier and 'secondary role' (Role 2) tier, which was optional. At the same time, the 'CA summary' tier was coded to identify stretches of constructed action (enactment) representing those roles. Under the CA summary tier, a set of tiers corresponding to individual $\mathrm{CA}$ articulators were annotated. These were tiers for eyegaze, face, head, mouth, torso and arms/hands.

\subsubsection{Constructed action (CA) tiers}

Because different CA articulators can be used simultaneously and/or sequentially with each other (Dudis 2004), the 'CA summary' tier was coded to identify all stretches of 
manual and non-manual instances of CA used to represent the same referent with one or several articulators (i.e. within the same character role).

Tiers for separate articulators were used to mark the manual and non-manual articulators used to express constructed action. Within a stretch of CA annotated in the CA summary tier, individual articulators marking CA could alternate. Stretches of CA were usually determined by the extent of each 'role' (see below). Therefore, CA is determined by the CA summary tier and Role(s) is determined by the Role tiers. Table 2 shows the CA tiers that were coded. A screenshot from ELAN showing an example of annotations on these various tiers is shown in Figure 2.

\begin{tabular}{|c|c|}
\hline Articulator tier & Description \\
\hline CA-eyegaze & $\begin{array}{l}\text { Break of eyegaze with addressee for purpose of enacting } \\
\text { referent }\end{array}$ \\
\hline CA-head & $\begin{array}{l}\text { Signer's use of his/her head to represent head } \\
\text { movement/posture of referent }\end{array}$ \\
\hline CA-face & $\begin{array}{l}\text { Signer's use of his/her facial expression to represent face of } \\
\text { referent }\end{array}$ \\
\hline CA-torso & $\begin{array}{l}\text { Signer's use of his/her torso to represent torso } \\
\text { movement/posture of referent }\end{array}$ \\
\hline CA-dom-arm/hand & $\begin{array}{l}\text { Signer's use of his/her dominant arm/hand to represent } \\
\text { arm/hand of referent }\end{array}$ \\
\hline CA-ndom-arm/hand & $\begin{array}{l}\text { Signer's use of his/her non-dominant arm/hand to represent } \\
\text { arm/hand of referent }\end{array}$ \\
\hline
\end{tabular}

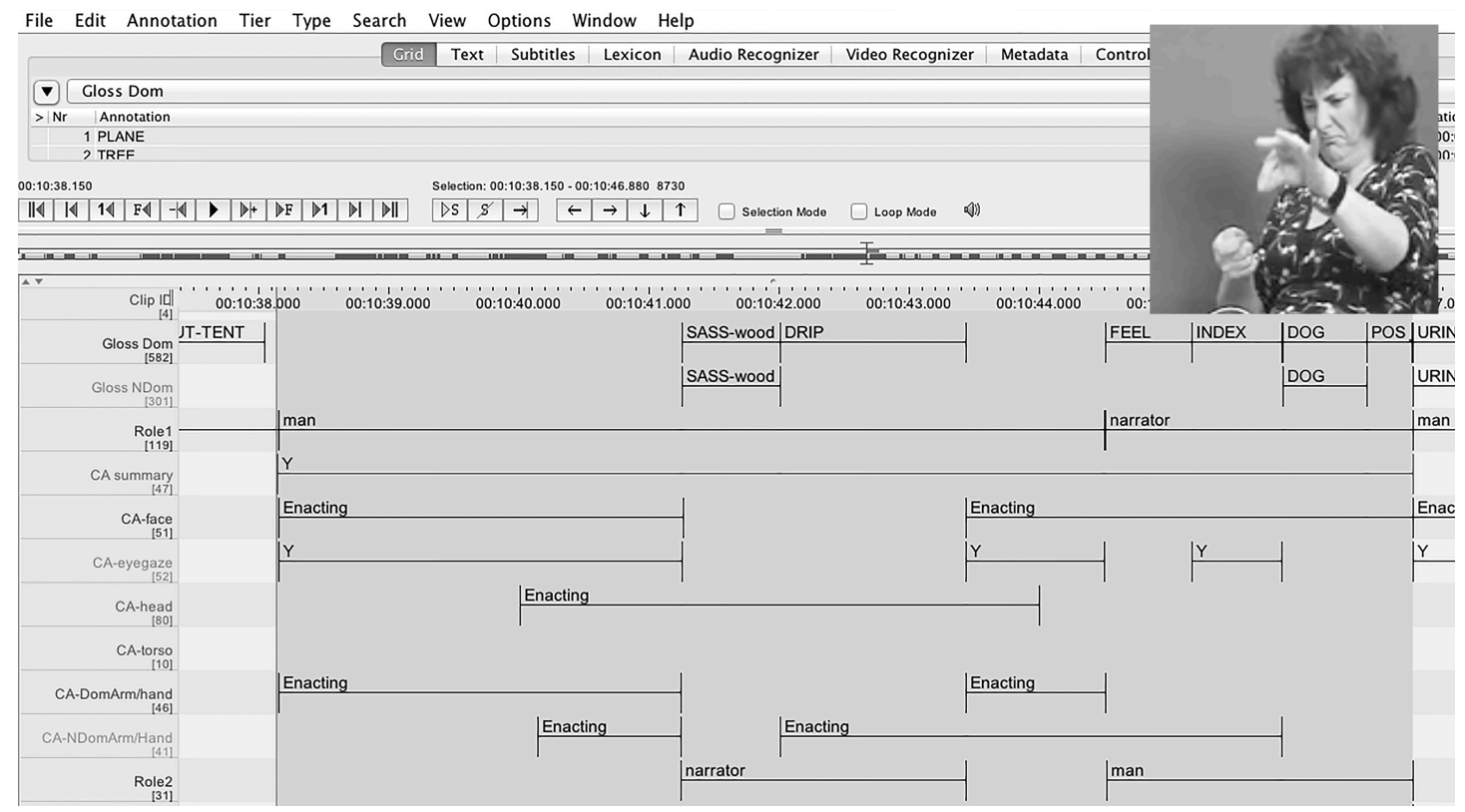

Figure 2. Stretch of CA with various articulators active at different times

\subsubsection{Eyegaze}

Eyegaze was coded as enacting when the participant clearly changed eyegaze (e.g. by breaking eyegaze with the addressee) for the purpose of enacting the referent from the stimulus clip. Not all instances of breaking eyegaze with the addressee were coded as enacting, only those in which the participant seemed to be taking on the role of a 
referent (for instance, the signer could also be looking at the laptop on which the cartoon had been shown). An example is shown in Figure 3, where the signer takes the role of the dog looking up to the man.

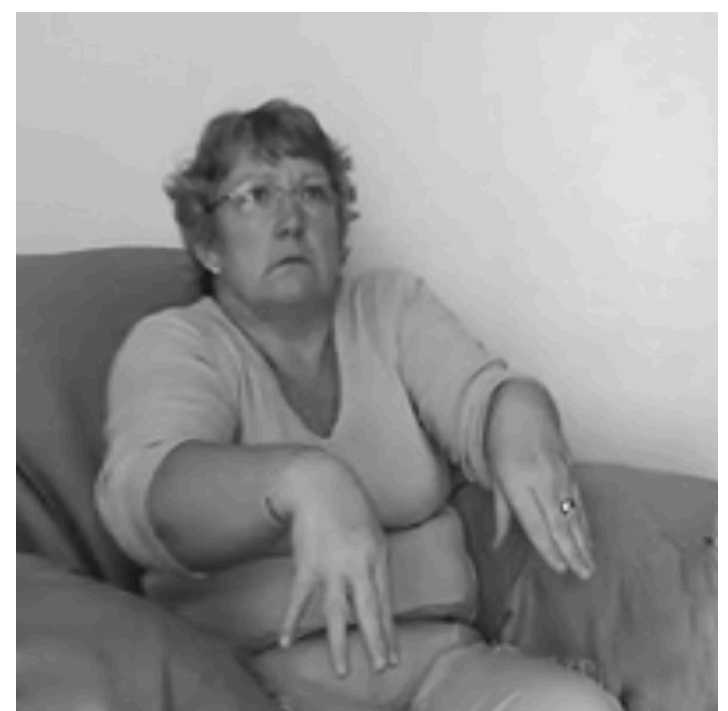

Figure 3. CA-eyegaze representing the dog looking up at the man

\subsubsection{Face}

The facial expression while describing the referents in the stimulus clips was coded as enacting when the participant was depicting the facial expression (or perceived facial expression) of the referent. For example, if the referent in the stimulus clip had a shocked facial expression in the elicitation clip and the participant mimicked this facial expression, this was coded as enacting within the Face tier. Figure 4 shows an example of enacting facial expression. The signer enacts the facial expression of the man looking at a sign in front of him just before he ignores its warning and chops it down.

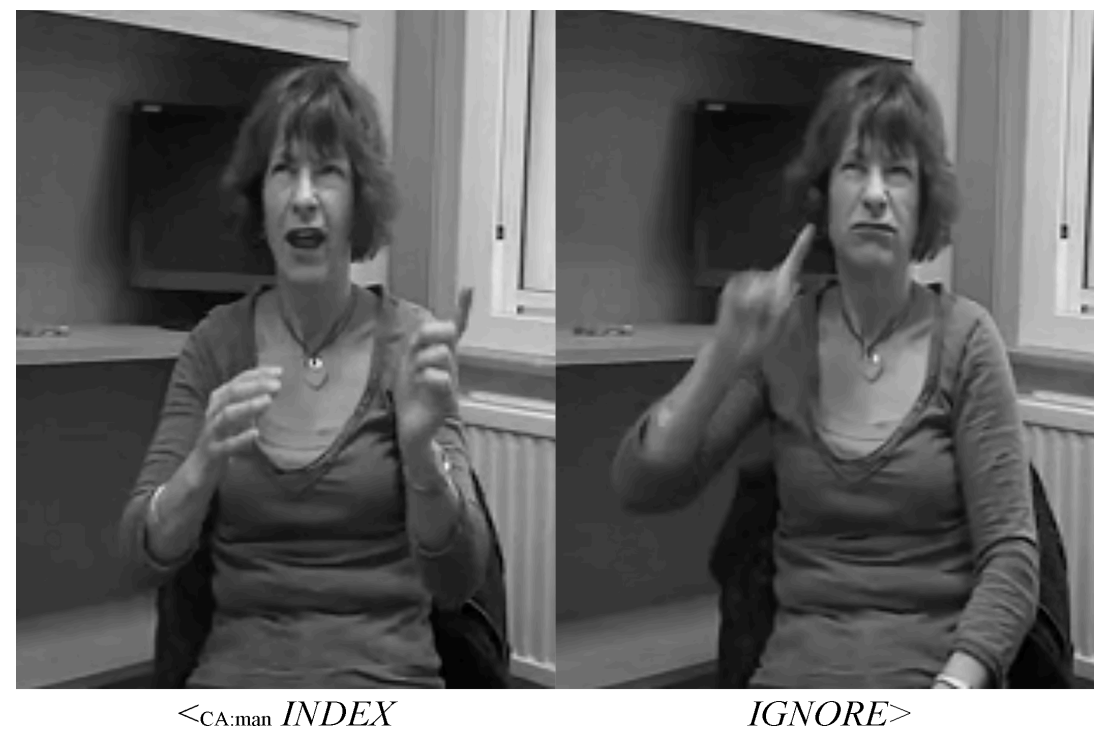

Figure 4. CA-face representing the facial expression of the man 
Facial expressions in which the participant was using his/her face in a way that mirrored the position or movement of the hands rather than enacting the facial expression of the referent (e.g. widening eyes co-occurring with opening of the hand rather than to represent widening eyes of the referent) were coded separately but were not included in the analysis. Grammatical facial expressions (e.g. the use of squinted eyes and pursed mouth to represent small size or refined movement) were not coded. Facial expressions that were affective and seemed to reflect the signer's own thoughts, emotions, etc. were also not coded.

A separate Mouth tier was used to code when the participant was using his/her mouth to enact or mimic the mouth of the referent. The mouth was coded as enacting only when the mouth pattern alone (and not the rest of the face) was enacting. If other characteristics of the face were also enacting, this was coded on the Face tier instead. It turns out that in the data set reported here, the mouth was never the sole marker of constructed action. (Other mouth patterns, including English mouthings and phonological/morphological mouth gestures, were coded separately but were not included in this analysis.) ${ }^{7}$

\subsubsection{Head}

The head was coded as enacting when the participant was clearly using his/her head to depict the head position or head movement of the referent. Figure 5 shows an example where the participant's head is tilted to the side to enact the dog sleeping. Head movements that seemed to mirror the movement of the hands rather than enact the head of the referent were coded separately but were not included in the analysis.

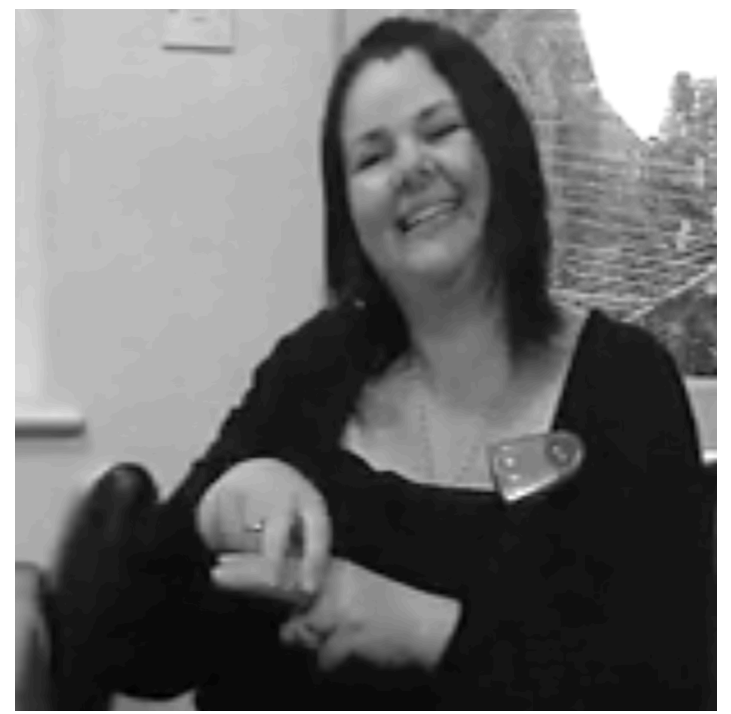

Figure 5. CA-head representing the head position of the dog as he falls asleep

\subsubsection{Torso}

Uses of the participant's upper body to depict the position or movement of the upper body of the referent were coded as enacting within the Torso tier. Figure 6 shows a signer enacting the leaning torso position of the dog while signing SLEEP. 
Cormier, K., Smith, S., \& Sevcikova, Z. (in press). Rethinking constructed action. Sign Language and Linguistics. (Submitted 4 April 2015. Check for latest version before citing.)

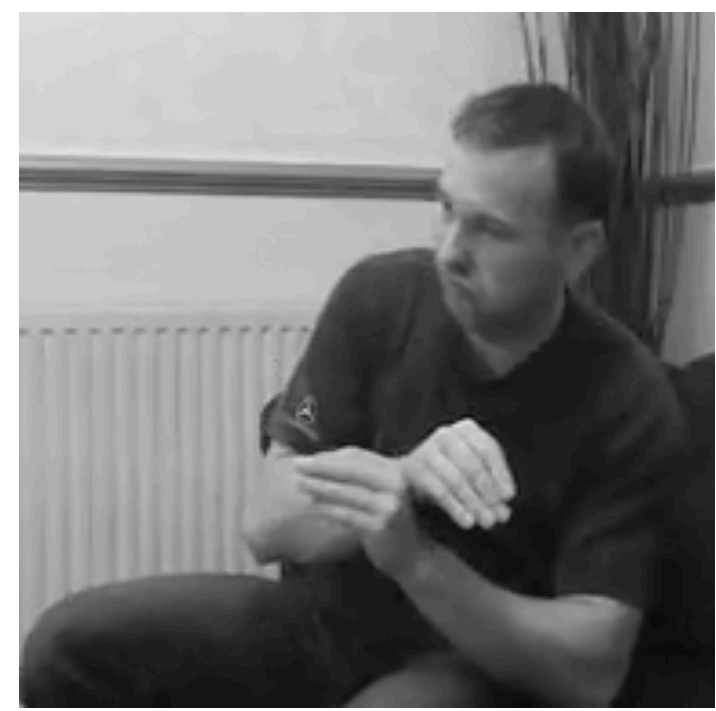

Figure 6. CA-torso representing torso position of the dog as he falls asleep

Lateral movements of the torso to mark constructed action, which have been described in the much of the literature to mark the start/end of a shifting of roles (e.g., Lee et al. 1997, Quer 2005, 2011) - i.e. those movements of shoulders/torso which do not enact the shoulders/torso of the referent - were not coded in this tier (these occurred very rarely in our data, as also found by Janzen (2004) for ASL - see $\$ 2.1$ above).

\subsubsection{Arm/hand}

There were two Arm/hand tiers, one for the dominant arm/hand and one for the nondominant arm/hand. These tiers were coded as enacting when the arm and/or hand of the participant was used to depict the arm and/or hand of the referent. This included any productive uses of handling or manipulative constructions that were depictive of the hand(s) of the referent handling or manipulating an object, and also any depictive movements of the arm(s). Figure 7 shows the signer taking the role of the man while he is holding a sign (left hand) and an axe to chop the sign (right hand). His hands are the only articulators enacting here, which was quite rare in our data. More often hands/arms were among other articulators that were also enacting simultaneously, as for example in Figure 8, which shows the signer representing the man's arms while he is walking onto the scene, with simultaneous use of eyegaze for CA. 


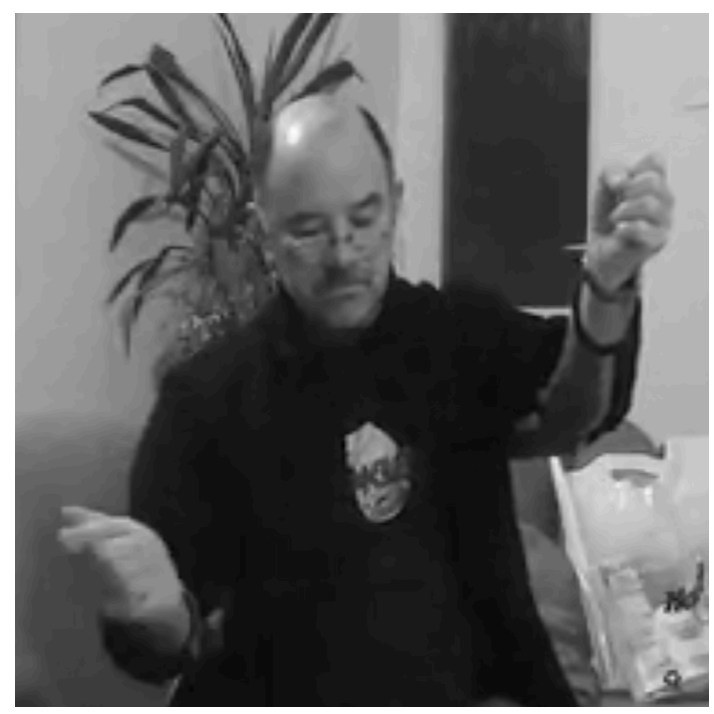

Figure 7. CA-dom-arm/hand and CA-nondom-arm/hand representing the man holding the signpost and chopping down the sign, with no other $\mathrm{CA}$ articulators active

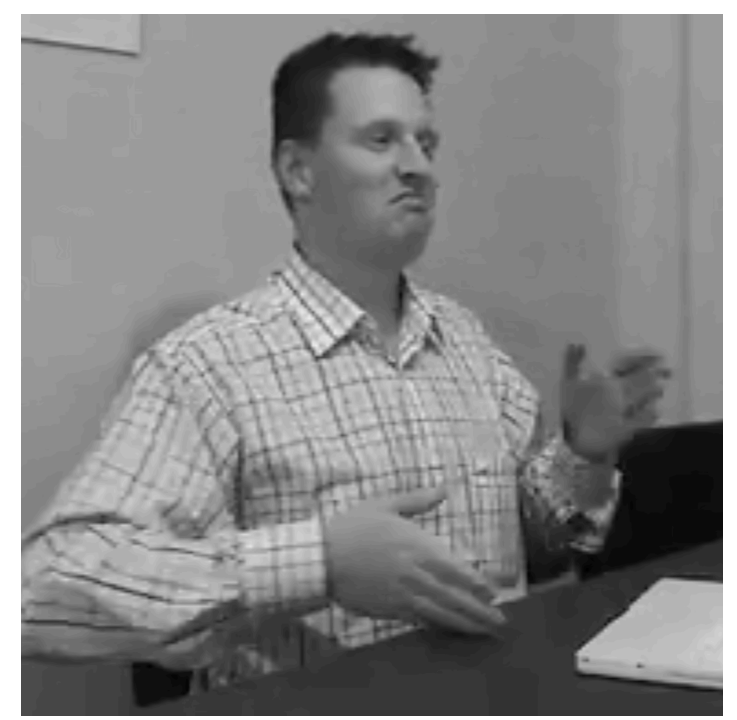

Figure 8. CA-dom-arm/hand and CA-nondom-arm/hand representing the man walking, with other CA articulators active

Arm/hand was coded as instrument rather than enacting when the hand was used to represent a held object, such as a flat hand used to represent the axe held by the man in the Pink Panther clip.

Uses of the hand which depicted handling or manipulation in a clearly non-iconic or non-productive way (e.g. the use of the one-handed sign POUR when representing the Pink Panther pouring water on the fire, who was doing the pouring with two hands) were coded separately as lexical signs on the gloss tiers, not on the Arm/hand tiers.

Constructions which represent handling or manipulation have been considered to be fully specified in the sign language lexicon by some (Supalla 1982, 2003, Zwitserlood 2003) and only partially specified by others (Liddell 2003). Here we take the view outlined in Cormier, Quinto-Pozos, Sevcikova \& Schembri (2012b) in which $\mathrm{CA}$ and representations of handling/manipulation are really the same phenomenon i.e. the hands of the signer represent the hands of the referent - and that these 
representations may be lexicalised to varying degrees. Thus the BSL signs in Figure 9 (COOK and TOOTHBRUSH) are lexical signs of handling, and the BSL signs in Figure 10 (RUN and BALLROOM-DANCE) are lexical signs of enactment which involve not only the hands but also the arms and/or torso. Any of these lexical signs could be used in a de-lexicalised (productive) form via CA. In fact, it can be difficult to distinguish lexical, semi-productive, and productive uses of each of these. This is what guided the coding of CA of the arms and hands for the current study.
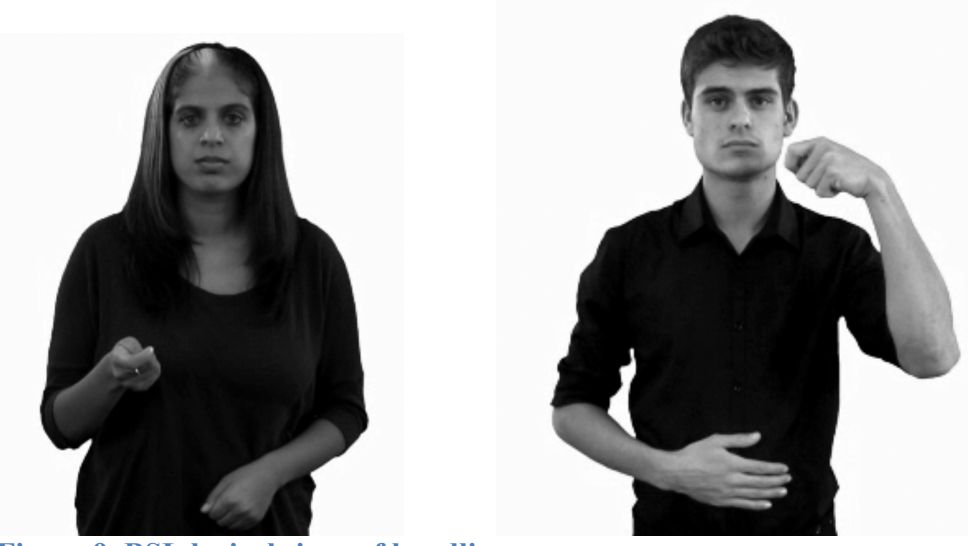

Figure 9. BSL lexical signs of handling: СООK, TOOTHBRUSH

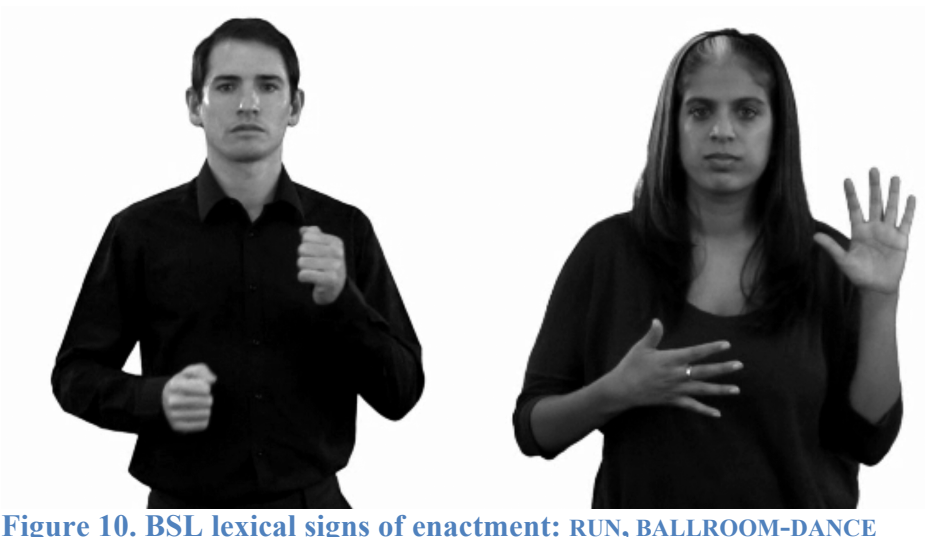

Figure 10. BSL lexical signs of enactment: RUN, BALLROOM-DANCE

\subsubsection{CA summary tier}

Because different CA articulators can be used simultaneously and/or sequentially with each other, we included a 'CA summary' tier, which identified stretches where CA was continuously used with one or more articulator to represent the same referent (i.e. within the same character role). Figure 2 above shows a highlighted stretch of narrative where the participant is using her head and face continuously to represent the character of the man in the cartoon. She also uses her eyegaze and her dominant and non-dominant hands for part (but not all) of this stretch. The entire highlighted section was considered to be a single token of CA.

\subsubsection{Role tiers}

Much of the earlier work on constructed action (e.g. Engberg-Pedersen's (1993) 'shifted attribution of expressive elements' as well as Metzger's (1995) 'direct action' and/or 'simultaneous direct and indirect action') place importance on the role that the 
signer is taking on - i.e. the referent(s) that the signer is meant to be representing, as does Dudis' (2004) notion of body partitioning which allows for representation of multiple roles simultaneously. Determining the signer's role in narratives is not always straightforward, and this may be one reason why the notion of role related to CA has not been clearly described in the literature.

Here we argue that it is important to identify the role(s) that a signer is taking on when using CA as this can help distinguish CA from other types of manual and nonmanual activity. Thus in our coding system, in addition to tiers for CA articulators, there were also tiers for role, both primary role (Role1) and secondary role (Role2). These tiers depended on the annotations from the CA articulator tiers (these tiers were closely related to the CA tiers). If no CA tiers were active, role 1 was coded as narrator, with no secondary role. Figure 11 shows an example when the signer used no involvement of the body or its parts to enact the character's actions and used a lexical sign to describe the event. Her head and eyegaze are directed to the screen where the cartoon was shown.

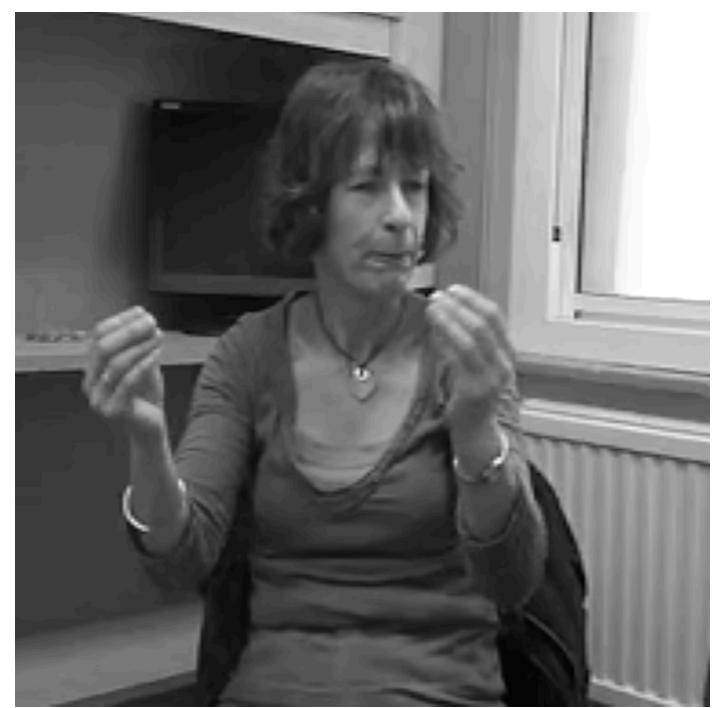

Figure 11. Full narrator role, BSL verb DISAPPEAR

If one or more CA tiers were active then either role 1 or role 2 had to be annotated as character. For the narratives elicited in this study, possible characters included man, dog, Pink Panther, bad dog, Wallace, Gromit or penguin.

One of these character roles was coded on the Rolel tier if the participant was clearly in one and only one role as determined by several active CA articulator tiers (and no lexical material). This is illustrated in Figure 12 where the signer is fully in the role of the character (i.e. the man) in the cartoon. 


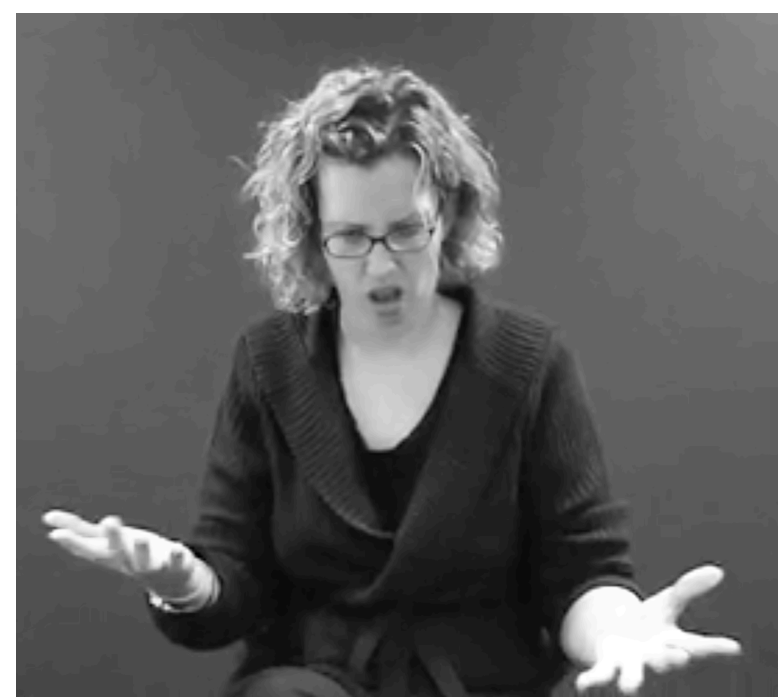

Figure 12. Full character role, single character representing man looking down

If the participant was representing a character using CA only very subtly (e.g. with only the face or only the head), the primary role (Role1) was coded as narrator with the character as Role2. This is demonstrated in Figure 13 where the signer's primary role is the narrator, with secondary role as the man. If more than one character was represented at a time, the role that seemed to be represented more strongly (e.g. by more CA articulators) was coded as Rolel and the less strong role was coded as Role2. ${ }^{8}$

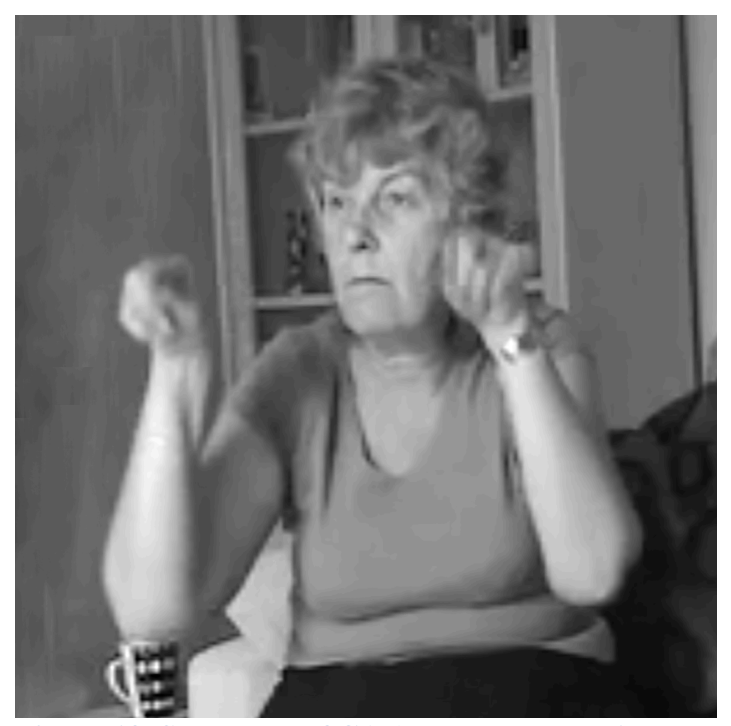

Figure 13. Subtle use of CA (narrator as role1, character as role2), representing man holding signpost and looking at it

The roles were determined by identifying whether there were other simultaneous elements involved such as lexical material or entity classifiers, and also by the number of CA articulators used and the extent to which the CA articulator tiers were active. The number of individual articulators was then used to predict whether the referent was represented as primary role or secondary role. 


\subsection{Types of CA}

Annotating the BSL narratives as described in the previous section resulted in a wide range of types of CA tokens, varying in the number of active CA-articulators and dominant role. The advantage of coding in this way is that it includes any activation of CA, irrespective of only one CA-articulator tier being active or, for instance, five. This is opposed to much previous research which has only taken into account the most overt instances of CA, thereby possibly excluding more subtle expressions of CA. One exception is Quinto-Pozos \& Mehta (2010) who considered degree of CA in relation to the intensity with which it is articulated (as noted above in $\$ 2.1$ ). However, Quinto-Pozos \& Mehta's coding system did not include identification of role.

The objective of the current paper is to propose a unified set of criteria for identification, coding and analysis of constructed action. As part of our coding system, we included a dependency principle between CA tiers and role tiers such that $\mathrm{CA}$ is determined by enacting articulators (degree) which, in exchange, determine the role(s) represented in the signer's narrative (form). If the CA tier (i.e. at least one articulator tier) was coded as active, then either Role1 or Role 2 had to be coded as something other than narrator, that is, any of the characters depicted in the cartoon (e.g. a man, Pink Panther, etc.). If none of the CA articulators were coded as active, Role 1 was coded by default as 'narrator'. For example, in cases when the signer breaks their eyegaze away from the addressee, consulting the Role tiers can help the coder decide whether the signer used eyegaze as a marker of CA because Role 1 or Role 2 were coded as 'character' or if the eyegaze has another function (see $\$ 2.1$ above) because neither Role was coded as 'character'. Likewise, if Role 1 or Role 2 were coded with a non-narrator role (a character), at least one CA articulator had to be coded as active. This dependency between CA tiers and Role tiers helped to keep native signer coder intuitions in check. For example, if coders felt intuitively that a signer was in a particular character role at any given time, and they were able to identify the $\mathrm{CA}$ articulators that contributed to that character role, this helped determine that a character role should be coded. Furthermore, the number of active articulators could also help justify the choice of a particular role.

Having annotated individual CA articulators in the adult and child data and identified Primary Role (Role1) and/or Secondary Role (Role2) using the Dependency Principle described above, four main patterns emerged. These are summarised in Table 3. Each CA type is described in the following sections.

\begin{tabular}{|c|c|c|c|}
\hline CA type & $\begin{array}{l}\text { Primary } \\
\text { Role }\end{array}$ & $\begin{array}{l}\text { Secondary } \\
\text { Role }\end{array}$ & Description \\
\hline none & narrator & none & $\begin{array}{l}\text { Signer narrating with no elements of CA. } \\
\text { Native signer intuition: "out" of character }\end{array}$ \\
\hline overt & character & none & $\begin{array}{l}\text { Clear use of CA (strong/many articulators) } \\
\text { with, no element of narration. Native signer } \\
\text { intuition: fully "in" character }\end{array}$ \\
\hline reduced & character & narrator & $\begin{array}{l}\text { Some use of CA (use of articulators for CA } \\
\text { between overt and subtle), with some } \\
\text { simultaneous narration (lexical material). } \\
\text { Native signer intuition: mostly "in" character }\end{array}$ \\
\hline subtle & narrator & character & $\begin{array}{l}\text { Some elements of CA (weak/few articulators), } \\
\text { possibly with simultaneous lexical material. } \\
\text { Native signer intuition: mostly "out" of }\end{array}$ \\
\hline
\end{tabular}


character but also a bit "in" character

Table 3. Summary of CA types (and lack of CA) based on Role(s)

\subsubsection{Overt CA (entirely character)}

In the case of overt CA, the signer uses no elements of explicit narration such as lexical signs or entity classifiers. In the dataset described here, we can be sure of the fact that the use of lexical signs and entity classifiers is explicit narration, since the cartoon clips and animations contained no signing. That is, anything other than purely representing what the character in the clip or animation was doing, has to be considered to be narration; it cannot be representation of dialogue, only of action. With overt CA the signer fully assumes the character role and depicts the actions or emotions of the character using corresponding articulators. The primary role (Role 1) would be typically coded as one of the characters in the cartoon. Secondary role (Role 2) would not be typically coded. Figure 14 shows an example of overt CA where the signer uses his face, head and the arms to enact the face body and arms of Wallace balancing on a train. The signer re-constructs (depicts) the scene and actions of the character it represents from the character's own point of view and narrates the event being fully 'in' character. There could be one or many articulators active but no lexical material or classifier constructions that would suggest any narrator role.

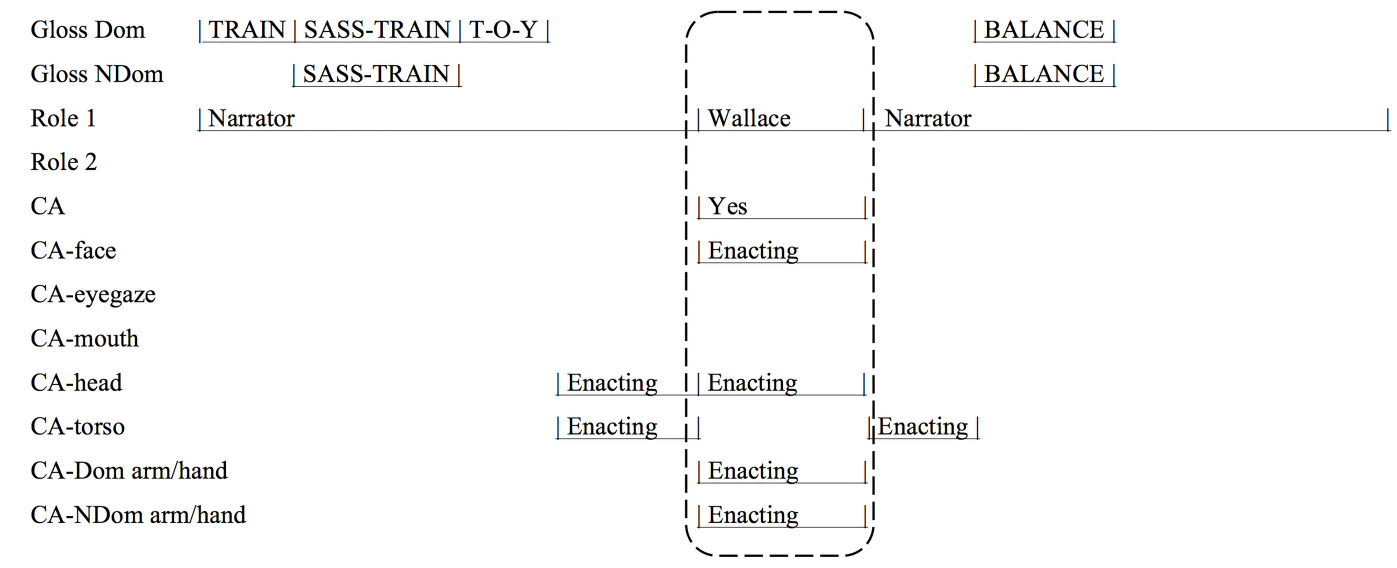

Figure 14. Example of tier activation in 'Overt CA' type

\subsubsection{Reduced CA}

Similar to Overt CA, with Reduced CA, the signer uses CA with many articulators active (e.g. face, head, torso, eyegaze) and assumes the character role ('in' character). However, the use of CA is reduced and some narration is involved. Native signer intuition is that the signer is primarily in character role, with only a small part narrator. Typically the small amount of narration involves the signer using some lexical material at the same time which is part of the narration. Figure 15 - the annotations for Figure 1 shown above - shows an example of the signer using her face, head and eyegaze to enact the face, head and eyegaze of the man arriving with a cooking pan in addition to lexical signs WANT COOK SOMETHING in order to provide narrative information. That is, the character in the cartoon was not signing that he 'wanted to cook something'. Instead, this is an inference made by the signer. 


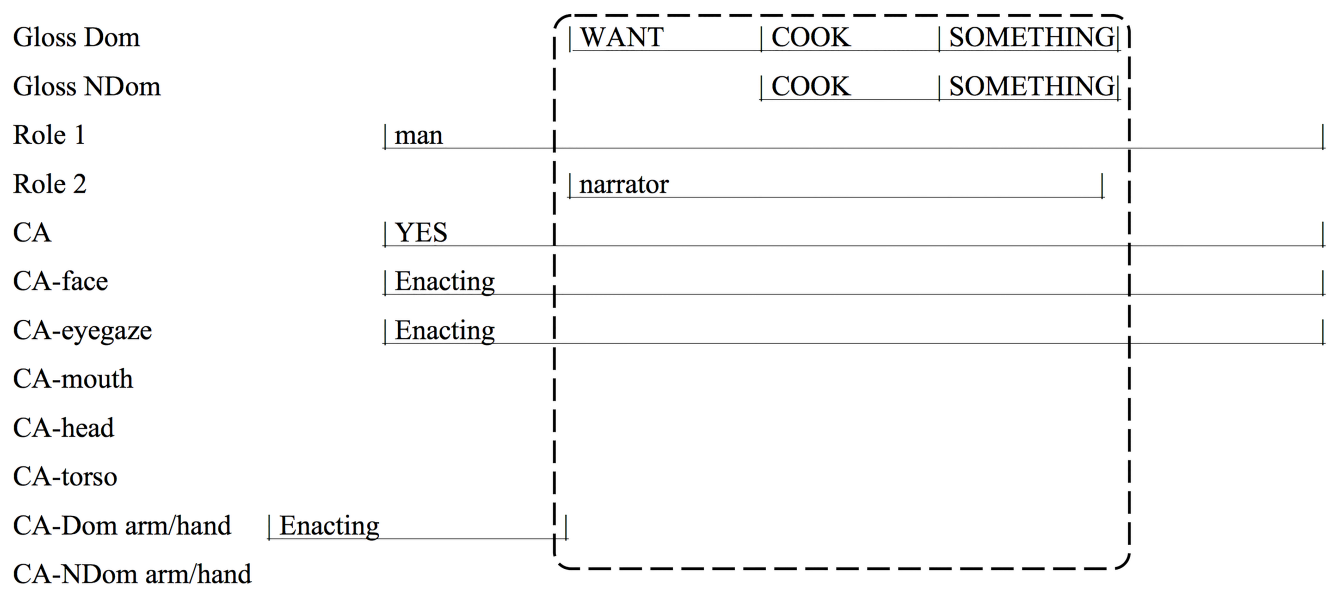

Figure 15. Example of tier activation in 'Reduced CA' type

\subsubsection{Subtle CA}

Here, the signer uses CA with only one or a few CA articulators active ('in' character); for example, only eyegaze is enacting the eyegaze of the character. This type of CA is described as subtle because the signer is primarily narrating but is using some CA simultaneously to represent some aspects of the referent subtly. With subtle $\mathrm{CA}$, primary role is narrator with secondary character role. The primary difference between Reduced CA and Subtle CA is the number (and/or intensity) of active CAarticulators. Figure 16 shows an example of the signer enacting only the face of the character with accompanying SASS classifier constructions. Note that only the face is active for $\mathrm{CA}$ in Figure 16 while the face and eyegaze are active in Figure 15.

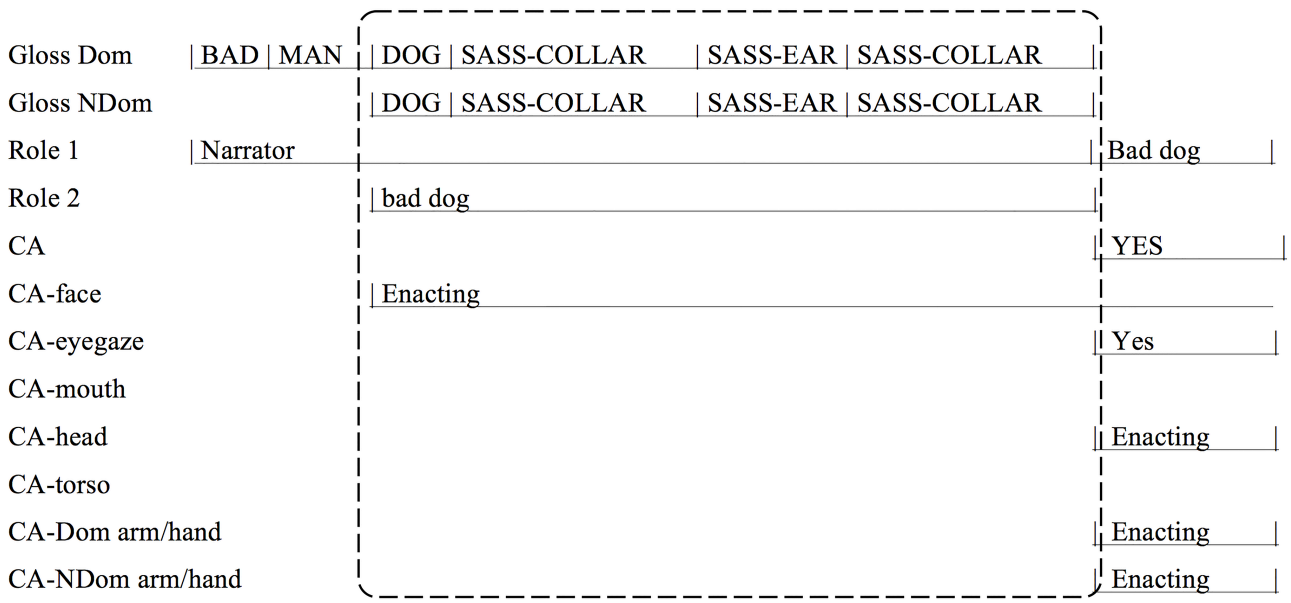

Figure 16. Example of tier activation in 'Subtle CA' type

\subsubsection{Mixed CA type (unattested)}

Finally, another possible form of CA that has not yet been attested in our data is shown in Table 4 below. This is when the signer takes on two (or more) character roles simultaneously. Each character role is marked by different articulators. There may or may not be an element of narration. This type of construction has been noted previously e.g. by Engberg-Pedersen (1993) and Dudis (2004) though the situations when it may be expected to occur are not well understood. The existence of a third (or fourth) Role is possible, for example, when there are more than two characters depicted in the scene. The signer can use a mix of narrator representations with two or 
more characters. In these instances of CA, it may be difficult to determine which role functions as primary, secondary etc.

\begin{tabular}{llll}
\hline CA type & $\begin{array}{l}\text { Primary } \\
\text { Role }\end{array}$ & $\begin{array}{l}\text { Secondary } \\
\text { Role }\end{array}$ & Description \\
\hline overt & character A & character B & $\begin{array}{l}\text { CA only, with representations of two } \\
\text { character roles simultaneously (each with } \\
\text { different articulators), with no element of } \\
\text { narration. Native signer intuition: "in" two } \\
\text { different characters at the same time }\end{array}$ \\
& &
\end{tabular}

\subsection{Summary}

As part of our coding process, we used a Dependency Principle between CA (as determined by CA summary tier, which was based on the CA articulator tiers) and Role (as determined by the Role tiers). If at least one CA articulator was coded as active, then either primary or secondary role had to be coded as one of the characters depicted in the story and vice-versa. The Dependency Principle between CA and Role helps to link the form and function of CA in discourse more consistently across various data samples. The Dependency Principle, when adopted by native signer annotators, helps keep in check native signer intuitions about the role(s) that the signer is adopting at any given time. We also suggested that the number of active CA articulators should help determine the prominence of Role - i.e. whether a character role is primary or secondary. We did not code for degree/intensity of CA in our data (cf. Quinto-Pozos \& Mehta 2010), although the intensity of CA articulators was used by coders make decisions with regards to character role 1 and role 2 . We also did not code for the three types of CA described above (overt, reduced, subtle) - these are merely descriptions of prototypes that emerged from our annotations after we had coded for CA articulators and role as described in $\$ 3.2 .1$ and $\$ 3.2 .2$. It may be best to consider these three prototypes as existing along a continuum of overtness of CA, such that a given token may not fall neatly into any one of these three.

To summarise, we have proposed that a Dependency Principle be used when annotating CA in sign language discourse: (1) Use native signer's intuition to help identify role, and (2) Use CA articulators to keep intuitions about role in check. Using this Dependency Principle, three main characteristics of CA have been identified in our data:

1. Three prototypes of CA depending on co-occurring Roles: overt, reduced or subtle, though these may be best considered as points along a continuum of overtness

2. Even within each prototype, a token of CA may be strong or weak (or in between), depending on number of CA articulators active and/or degree of activation of one or more articulators

3. CA may occur over any length of discourse

\subsection{Alternatives for less detailed annotation of $\mathrm{CA}$ or quotative $\mathrm{CA}$}

The purpose of our CA annotation scheme was to understand in detail how and when signers use $\mathrm{CA}$ in relation to classifier constructions and other types of signs in narrative discourse. Therefore, this level of detail was what was needed in our study. 
However, this level of detail might not be needed in every study where annotation of CA would be useful. Here we describe some possible alternatives for less detailed annotation of CA or quotative CA using the same principles as described here.

\subsubsection{Primary and secondary role tiers versus Summary role tier}

When there was at least one CA articulator tier active, our project coders used a combination of criteria to determine whether the character represented was primary or secondary role: number of CA articulators active, degree of activation of each, and their own native signer intuitions. Each of these were used along with the Dependency Principle described in §3.3. However, even with these criteria and Dependency Principle, it can be difficult to determine whether a particular token of CA had character as primary role and narrator as secondary role (i.e. reduced CA) or narrator as primary role and character as secondary role (i.e. subtle CA). For some researchers, depending on the amount of detail needed, it may be adequate to have a single Role tier instead of multiple Role tiers. The values for the single Role tier could be: narrator (for no CA), a specific character/referent, e.g. Pink Panther or dog or Wallace (for overt CA), or a combined narrator/character, e.g. narrator/dog or narrator/Wallace. The latter would be a combination of reduced and subtle CA and could instead be called non-overt CA. This is essentially the approach adopted by Earis (2008) and Earis \& Cormier (2013).

\subsubsection{Individual CA articulator tiers versus Summary-CA tier}

Because our project aimed to explore CA in some detail, we coded for individual CA articulators via articulator tiers (e.g. CA-head, CA-face, etc, as described in §3.2.1), and additionally a CA-summary tier to identify stretches of CA where there might be multiple, overlapping $\mathrm{CA}$ articulators without a single articulator active during the entire stretch. This was useful for us to be able to apply the Dependency Principle, because it was straightforward to check which and how many articulators were active. Another possibility if information about individual articulators is not needed would be to use only a CA-summary tier. This could work in a similar way as long as annotators are aware of the need to consider all possible articulators when determining primary versus secondary role and/or the overtness of the CA involved.

\subsubsection{CA types for quotative CA}

Although our data consist only of non-quotative $\mathrm{CA}$, it seems plausible that the same range of CA types may exist for quotative $\mathrm{CA}$ as for non-quotative $\mathrm{CA}$. Indeed, several of our CA tokens represented thoughts which could be considered to be imagined utterances (e.g. Figure 15). Table 5 is a revised version of Table 3, adapted for quotative CA. Again, these are best thought of as prototypes along a continuum of overtness, and it is likely that any given token could fall anywhere along this continuum.

\begin{tabular}{llll} 
CA type & $\begin{array}{l}\text { Primary } \\
\text { Role }\end{array}$ & $\begin{array}{l}\text { Secondary } \\
\text { Role }\end{array}$ & Description \\
\hline none & narrator & none & $\begin{array}{l}\text { Signer narrating with no elements of CA. } \\
\text { Native signer intuition: "out" of character } \\
\text { Quoted utterance of character with } \\
\text { simultaneous clear use of CA (strong/many } \\
\text { articulators). Native signer intuition: fully "in" } \\
\text { character }\end{array}$ \\
& character & none & \\
& &
\end{tabular}


Cormier, K., Smith, S., \& Sevcikova, Z. (in press). Rethinking constructed action. Sign Language and Linguistics. (Submitted 4 April 2015. Check for latest version before citing.)

reduced character narrator Quoted utterance of character with some use of CA (use of articulators for CA between overt and subtle). Native signer intuition: mostly "in" character

subtle narrator character Quoted utterance of character with some elements of CA (weak/few articulators). Native signer intuition: mostly "out" of character but also a bit "in" character

Table 5. Proposed quotative CA types (and lack of CA) based on Role(s)

\section{Recommendations for defining and annotating Constructed Action and Role Shift}

We would like to revisit the working definition of Constructed Action, as previously suggested in $\S 1$. We suggest that Constructed Action is a stretch of discourse (however short or long) that represents one role or combination of roles depicting actions, utterances, thought, attitudes and/or feelings of referents other than the signer (narrator). Thus, Figure 17 shows two tokens of Constructed Action. Furthermore, there are three types of CA, based on the degree to which the non-narrator role(s) appear to be explicitly realised. This system should enable a more systematic coding across data sets and allows for more consistent cross-study comparison.

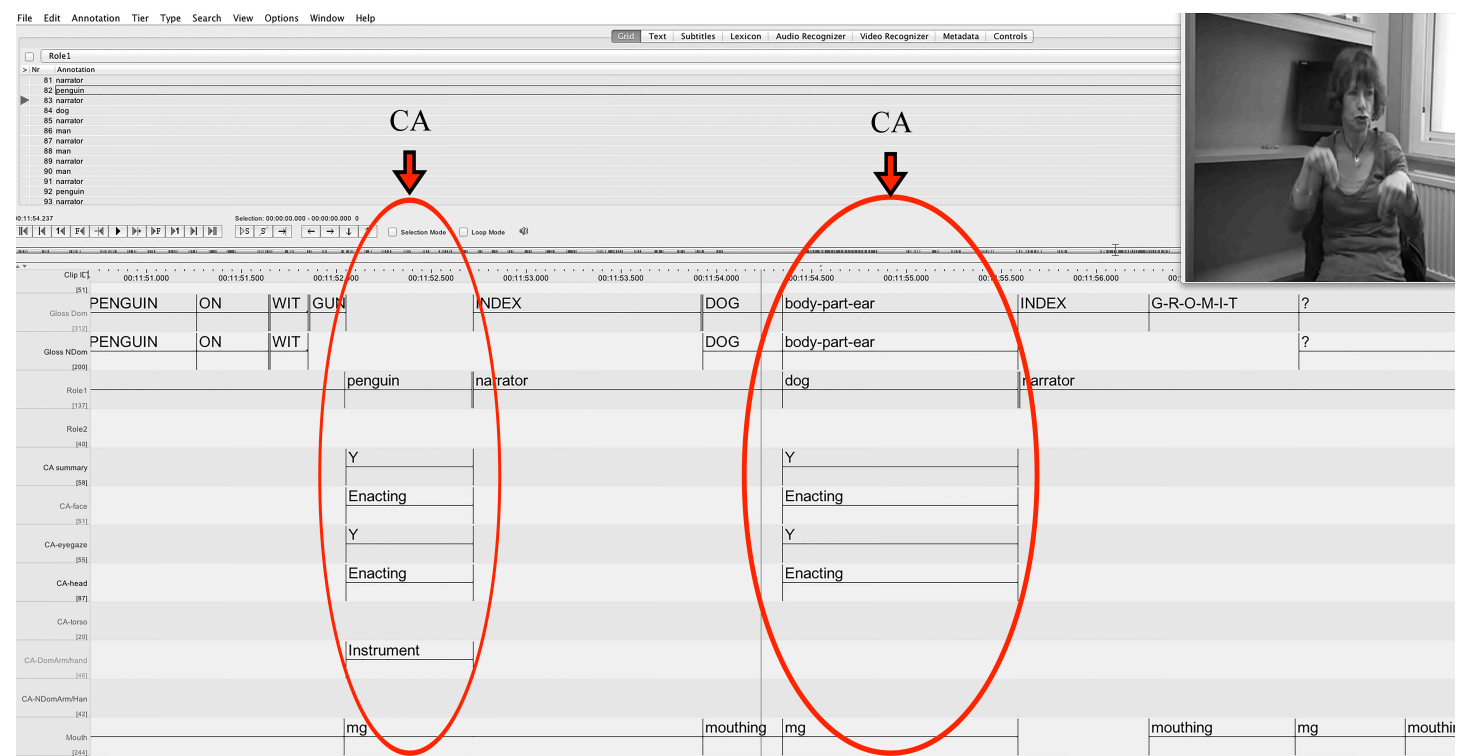

Figure 17. Example of two Constructed Action tokens in narrative (one as penguin and one as dog), not role shift

Rather than using the terms Constructed Action and Role Shift interchangeably (which is what some researchers appear to do), we suggest that Constructed Action as defined in this paper should be distinguished from Role Shift. Unlike CA which is a stretch of discourse (however short or long) that represents one role or a simultaneous combination of roles, we suggest that Role Shift is characterised as a shift between roles. This may be a shift between a period of narration (narrator role) and a period of non-narrator role (character role) expressed via CA, or between two character roles expressed by $\mathrm{CA}$ and determined by the $\mathrm{CA}$ articulators. So, there could be a number 
of different roles switching within a period of time in which CA articulators are active, with the articulators alternating or simultaneous, but each set of articulators would be aligned with the related role. This may be a shift between a period of narration and a period of non-narrator role expressed via $\mathrm{CA}$, or between more than one non-narrator role (each expressed via $\mathrm{CA}$ ). Figure 18 shows an example of Role shift (in the sense that we are now using it) which marks the shift between periods of $\mathrm{CA}$ and periods with no CA. In this example, four role shifts are highlighted. The signer's primary role as narrator (marked by no CA) switches to penguin (marked by overt CA), then to narrator (no CA) then to dog (overt CA) and back to narrator (no CA). Each shift is flagged by a number. Within this Role Shift in and out of different roles, there are two tokens of Constructed Action: one as a penguin, and one as a dog.

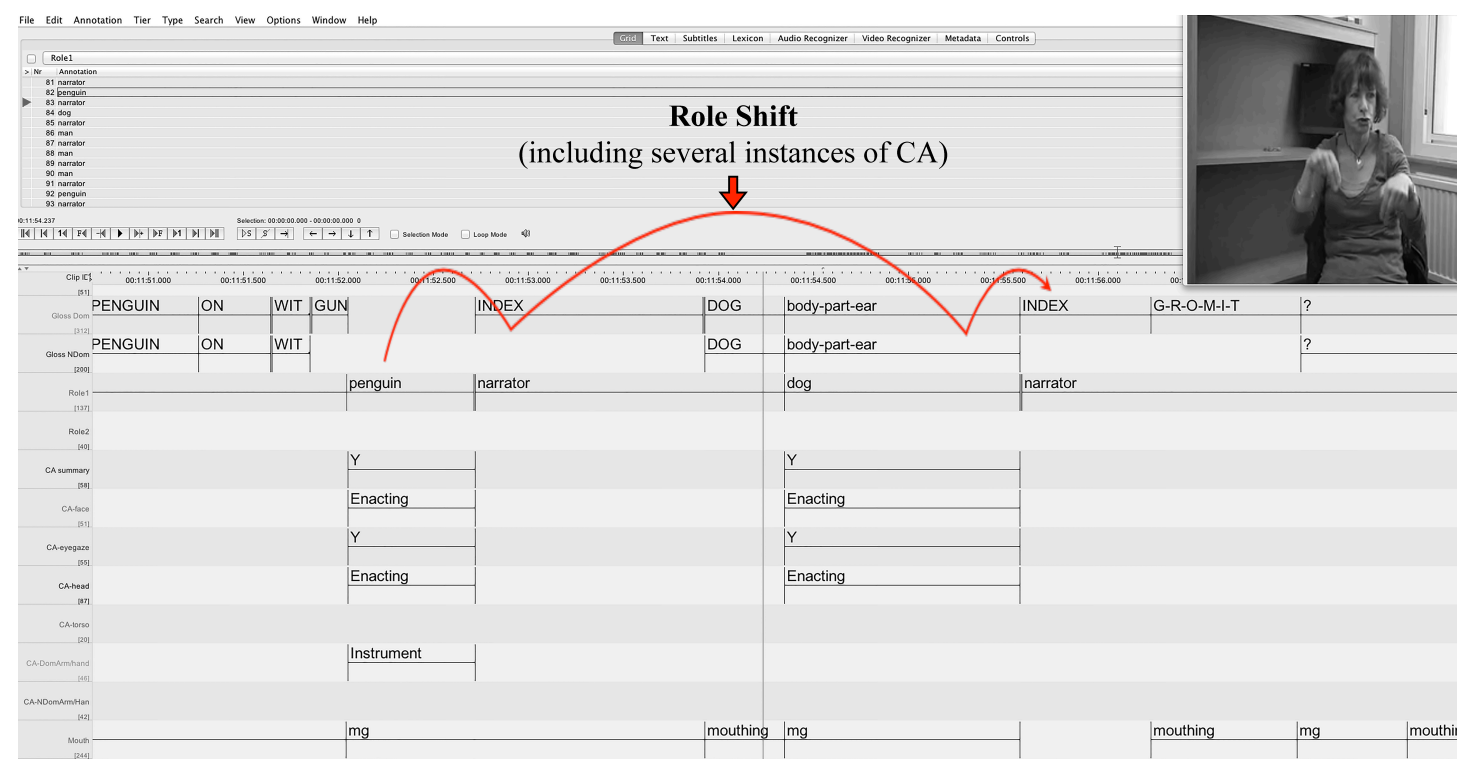

Figure 18. An example of Role Shift: four shifts from narrator (1) to penguin (2) to narrator (3) to dog (4) to narrator.

We suggest that this distinction between Constructed Action and Role Shift, along with a distinction between the three types of CA described above (overt, reduced, subtle), can help reconcile previous seemingly contradictory claims about the nature of $\mathrm{CA}$, as described in the following section.

\section{Reconciling previous claims about Constructed Action}

A more unified definition of CA can help reconcile previous claims about ease or difficulty of acquisition of CA. By distinguishing between different degrees of CA and CA types, and also between Constructed Action and Role Shift, it may be possible to explain the developmental patterns of these devices by deaf children and learners of sign language as L2, and to reconcile other claims in the literature that also seem contradictory.

For instance, as noted in $\S 2$, Poulin \& Miller (1995) argue that an involved comment that is directly associated with the content of the event is acceptable when uttered during referential shift but a neutral comment is not, and a neutral comment is only acceptable when uttered during the unmarked form - i.e. outside of referential shift. It seems that what Poulin and Miller are referring to as 'marked RS' is overt 
$\mathrm{CA}$ (character role) and 'unmarked RS' is no CA (narrator role). Adding involved comments during CA reduces the degree of CA as it implies another secondary role (mostly narrator but can be another character in some cases), which we define here as either reduced or subtle CA. During stretches of overt CA, neutral comments (metacomments) would not occur as there would be no narrator role (primary/secondary).

In terms of acquisition, children might start using more overt CA in early communication, e.g. being fully 'in' character. 'Acting out' actions and events of individual referents is something young children - both deaf and hearing - master relatively early on (Loew 1984, Schick 1987, McNeill 1992). It is likely that productions of individual tokens of CA occur earlier in children compared to Role Shift, where CA is embedded in some narration. It is also likely that less overt CA forms (e.g. subtle or reduced with both character and narration representation, or several character representations) are acquired later than more overt CA, and that use of CA simultaneously with other types of constructions takes longer to emerge. For example, previously we have showed that deaf children at age 6 were not yet adultlike in their simultaneous use of CA with lexical signs and/or classifier constructions (Cormier, Smith \& Sevcikova 2013). Similarly, other research suggests that constructions using multiple perspectives puts more cognitive demand on processing and are acquired later (Morgan 2002, Slobin et al. 2003).

These patterns might help explain some of the claims about ease or difficulty of 'role shift.' Casey (2003) suggested that "role-shift-like devices" are easily innovated and acquired early (see $\$ 2.1$ above). We suspect that Casey might be referring to the type of CA described here as overt CA which involves a character role only.

Given the acquisition patterns noted so far, we would suggest two developmental trajectories of CA, from earliest to latest: (1) Overt CA $>$ Reduced CA $>$ Subtle CA. Also: (2) CA > Role Shift. ${ }^{9}$

However, the patterns described by Emmorey and Reilly (1998) introduce some complications. Emmorey and Reilly suggested that "reported action" is acquired later than "direct quotation." If "reported action" is understood as overt CA and "direct quotation" is understood as reduced or subtle CA, this would be at odds with the trajectory noted above. However, it seems that their reported action may be referring to a reduced CA type, with character Role1 and narrator Role2, that is acquired later than direct (possibly overt) quotation, since all of the examples they provide are examples of CA articulated simultaneously with lexical signs. This would make more sense, since one would expect children to be able to directly quote the utterances of someone, both nonmanual $\mathrm{CA}$ and lexical material representing the same referent, before being able to produce narration while in character.

If this is true, then a revised developmental trajectory might be as follows: Overt CA (non-quotative) $>$ Overt CA (quotative, CD) $>$ Reduced CA $>$ Subtle CA. We did not observe any quotative uses of $\mathrm{CA}$ in our data because the stimuli contained no accessible utterances, so our data cannot support or refute this revised trajectory.

To summarise, while others have recognised the simultaneous use of narration with CA (e.g., Metzger 1995, Poulin \& Miller 1995), few have sought to explicitly distinguish overt CA from less overt types. To our knowledge, this is the first attempt to describe multiple types of non-overt CA. Additionally, the consideration of whether $\mathrm{CA}$ is quotative (representing utterances) or not (representing actions) may be important in teasing apart the various types and functions of CA. 


\section{General implications for sign language research}

We return to the issue of eyegaze as used for CA versus grammatical agreement, as noted in $\$ 2.3$. In studies of sign language grammar and morphosyntax it is important to consider various types of CA, as this could affect the analysis used. As noted, it is important for researchers to be clear about their use of terms such as CA and role shift not just when this is the primary phenomenon under study. Although de Beuzeville et al.'s (2009) finding that modification of directional verbs favoured the co-occurrence of CA was not specifically about eyegaze, they certainly did include eyegaze as a possible marker of CA. Because neither Neidle et al. (i.e. Bahan 1996, Lee et al. 1997, Neidle et al. 2000) nor Thompson (2006) consider CA as a possible explanation for the patterns they describe, it is difficult to know if these studies on Auslan and ASL are describing the same or different phenomena.

Separately, Liddell \& Metzger (1998) argued against eyegaze as an agreement marker, but they did so based on examples only of strongly overt CA. They argued that when constructed action is marked by the majority of articulators as can be seen in overt CA where the signer is fully "in" the character role, the information that is expressed is more than simply spatial loci associated with the subject and object - it also includes information about the overall mental space which the signer is communicating about and which the addressee is constructing. We would argue that whether the CA is overt or not - i.e. even with reduced or subtle CA - eyegaze can be the only marker of CA. That is, it is possible to be partially or fully 'in' character without the use of very many articulators. Thus even when only eyegaze is used to mark spatial locations in sign language discourse, CA needs to be considered as a possible explanation for what has been described by Neidle et al. and Thompson as "agreement". A recent study has done just this, looking at the co-occurrence of various types of CA (including subtle CA) with indicating verbs in BSL. Findings suggest that the use of CA, as defined in the current paper, along with particular uses of space and the body co-occurring with indicating verbs suggest that these verbs favour use space which is motivated rather than arbitrary (Cormier, Fenlon \& Schembri under review).

The model for defining $\mathrm{CA}$ in this paper also has implications for other sign language researchers, beyond studies specifically on eyegaze or CA itself. For example, we have found that consideration of different types of CA has helped to resolve issues with regards to scoring reproductions of stimuli that (might) include CA in sentence repetition tasks (e.g., Cormier et al. 2012a). To be able to control or recognise and account for $\mathrm{CA}$ produced during sentence repetition requires an understanding of different types of CA and how they are marked. For example, if a sign model produces a stimulus sentence with overt CA, would the use of reduced CA in the repeated version be considered an acceptable deviation, or an error? Likewise, if subtle CA (few/weak use of articulators) is produced during a stimulus sentence, would the use of overt CA (more/strong use of articulators) be considered an acceptable deviation or an error? With careful consideration of various types of CA and how it can be manifested, issues such as these can be considered and controlled for in the design phase of the study.

\section{Summary and conclusions}

We have presented problems with assumptions about Constructed Action in sign languages which has led to some apparent contradictions about the nature of this 
phenomenon. We have shown that, in carefully defining the phenomenon in question and providing criteria for its identification, applying these criteria to usage data leads to particular emerging types of Constructed Action. Identifying these types, and also distinguishing tokens of Constructed Action from Role Shift (i.e. shifts between Roles which may be marked via CA) can help resolve some of the apparent contradictions in the literature.

Additionally, the Dependency Principle between CA and Role that we have proposed here should help in identifying and annotating the form and function of CA in discourse more consistently across various data samples and keep coders' intuitions in check. This system enables systematic coding across data sets and allows for a consistent cross-linguistic comparison.

\section{References}

Bahan, Ben. 1996. Non-manual realization of agreement in American Sign Language. $\mathrm{PhD}$ dissertation dissertation, Boston University.

Bahan, Ben \& Samuel Supalla. 1995. Line segmentation and narrative structure: A study of eyegaze behavior in American Sign Language. In Karen Emmorey \& Judy Reilly (eds.), Language, Gesture and Space, 171-91. Mahwah, NJ: Lawrence Erlbaum Associates.

Bavin, Edith L. in press. Widening the field: the process of language acquisition. Behavioral and Brain Sciences,

Casey, Shannon. 2003. "Agreement" in gestures and signed languages: The use of directionality to indicate referents involved in actions. $\mathrm{PhD}$ dissertation dissertation, University of California.

Coates, Jennifer \& Rachel Sutton-Spence. 2001. Turn taking patterns in Deaf conversation. Journal of Sociolinguistics 2.1, 3-34.

Cormier, Kearsy, Robert Adam, Katherine Rowley, Bencie Woll \& Joanna Atkinson. 2012a. The British Sign Language Sentence Reproduction Test: Exploring age-of-acquisition effects in British deaf adults. Paper presented at Experimental studies in sign language research: Sign language workshop at the Annual Meeting of the German Linguistics Society (DGfS), Frankfurt am Main, Germany.

Cormier, Kearsy, Jordan Fenlon \& Adam Schembri. under review. Indicating verbs in British Sign Language favour motivated use of space.

Cormier, Kearsy, David Quinto-Pozos, Zdenka Sevcikova \& Adam Schembri. 2012b. Lexicalisation and de-lexicalisation processes in sign languages: Comparing depicting constructions and viewpoint gestures. Language and Communication 32.4, 329-48.

Cormier, Kearsy, Sandra Smith \& Zed Sevcikova. 2013. Predicate structures, gesture and simultaneity in the representation of action in British Sign Language: Evidence from deaf children and adults. Journal of Deaf Studies and Deaf Education 18.3, 370-90.

Cormier, Kearsy, Sandra Smith \& Martine Zwets. 2013. Framing constructed action in British Sign Language narratives. Journal of Pragmatics 55, 119-39.

de Beuzeville, Louise, Trevor Johnston \& Adam Schembri. 2009. The use of space with indicating verbs in Australian Sign Language: A corpus-based investigation. Sign Language and Linguistics 12.1, 52-83. 
Cormier, K., Smith, S., \& Sevcikova, Z. (in press). Rethinking constructed action. Sign Language and Linguistics. (Submitted 4 April 2015. Check for latest version before citing.)

Dudis, Paul G. 2004. Body partitioning and real-space blends. Cognitive Linguistics 15.2, 223-38.

Earis, Helen. 2008. Point of view in narrative discourse: A comparison of British Sign Language and spoken English. $\mathrm{PhD}$ diss. dissertation, University College London.

Earis, Helen \& Kearsy Cormier. 2013. Point of view in British Sign Language and spoken English narrative discourse: the example of 'The Tortoise and the Hare'. Language and Cognition 5.4, 313-43.

Emmorey, Karen \& Judy Reilly. 1998. The Development of quotation and reported action: Conveying perspective in ASL. In Eve Clark (ed.), Proceedings of the Twenty-ninth Annual Child Language Research Forum, Sign, 81-90. Stanford, CA: CSLI Press.

Engberg-Pedersen, Elisabeth. 1993. Space in Danish Sign Language. Hamburg: Signum Press.

Engberg-Pedersen, Elisabeth. 1995. Point of View Expressed Through Shifters. In Karen Emmorey \& Judy Reilly (eds.), Language, Gesture \& Space, Sign, 13354. Hillsdale, NJ: Lawrence Erlbaum Associates.

Goswell, Della. 2011. Being There: Role Shift in English to Auslan Interpreting. In Lorraine Leeson, Myriam Vermeerbergen \& S. Wurm (eds.), Signed Language Interpreting: Preparation, Practice and Performance. St. Jerome.

Hansen, Martje \& Jens Hessman. 2007. Matching propositional content and formal markers: Sentence boundaries in a DGS text. Sign Language and Linguistics 10.2, 145-75.

Hermann, Annika \& Markus Steinbach. 2007. When 'I' is not I - Quotation in sign languages. Linguistische Berichte 15, 153-79.

Hermann, Annika \& Markus Steinbach. 2012. Quotation in sign languages. A visible context shift. In Ingrid van Alphen \& Isabelle Buchstaller (eds.), Quotatives: Cross-linguistic and Cross-disciplinary Perspectives, 203-30. Amsterdam: John Benjamins.

Hosemann, Jana. 2011. Eye gaze and verb agreement in German Sign Language: A first glance. Sign Language \& Linguistics 14, 76-93.

Janzen, Terry. 2004. Space rotation, perspective shift, and verb morphology in ASL. Cognitive Linguistics 15.2, 149-74.

Johnston, Trevor, Jane van Roekel \& Adam Schembri. 2015. On the Conventionalization of Mouth Actions in Australian Sign Language. Language and Speech,

Johnston, Trevor, Myriam Vermeerbergen, Adam Schembri \& Lorraine Leeson. 2007. 'Real data are messy': Considering cross-linguistic analysis of constituent ordering in Auslan, VGT, and ISL. In Pamela M. Perniss, Roland Pfau \& Markus Steinbach (eds.), Visible Variation: Comparative Studies on Sign Language Structure, 163-206. Berlin: Mouton de Gruyter.

Kegl, Judy. 1995. The Manifestation and Grammatical Analysis of Clitics in American Sign Language. Chicago Linguistic Society 31.2, 140-67.

Kooij, Els van der, Wim Emmerick \& Onno Crasborn. 2004. Prosodic features of focus in NGT. Paper presented at Theoretical Issues in Sign Language Research 8, Barcelona, Spain.

Lee, Robert G., Carol Neidle, Dawn MacLaughlin, Ben Bahan \& Judy Kegl. 1997. Role shift in ASL: A syntactic look at direct speech. In Carol Neidle, Dawn MacLaughlin \& Robert G. Lee (eds.), Syntactic structure and discourse 
Cormier, K., Smith, S., \& Sevcikova, Z. (in press). Rethinking constructed action. Sign Language and Linguistics. (Submitted 4 April 2015. Check for latest version before citing.)

function: An examination of two constructions in American Sign Language, 24-45. Boston, MA: American Sign Language Linguistic Research Project, Boston University.

Lentz, Ella Mae. 1986. Teaching Role Shifting. In Carol A. Padden (ed.), Proceedings of the Fourth National Symposium on Sign Language Research and Teaching, Sign, 58-69. Silver Spring, MD: NAD.

Liddell, Scott K. 2003. Grammar, gesture and meaning in American Sign Language, Sign. Cambridge: Cambridge University Press.

Liddell, Scott K. \& Melanie Metzger. 1998. Gesture in sign language discourse. Journal of Pragmatics 30, 657-97.

Lillo-Martin, Diane. 1995. The point of view predicate in American Sign Language. In Karen Emmorey \& Judy Reilley (eds.), Language, Gesture and Space, Sign, 155-70. Mahwah, NJ: Lawrence Erlbaum Associates.

Lillo-Martin, Diane. 2012. Utterance reports and constructed action in sign and spoken languages. In Roland Pfau, Markus Steinbach \& Bencie Woll (eds.), Sign Language - An International Handbook (Handbooks of Linguistics and Communication Science), 365-87. Amsterdam: Mouton de Gruyter.

Loew, R.C. 1984. Roles and Reference in American Sign Language: A Developmental Perspective. $\mathrm{PhD}$ dissertation dissertation, University of Minnesota.

McKee, Rachel \& David McKee. 1992. What's so hard about learning ASL? Sign Language Studies 21.75, 129-58.

McKee, Rachel, Adam Schembri, David McKee \& Trevor Johnston. 2011. Variable 'subject' presence in Australian Sign Language and New Zealand Sign Language. Language Variation and Change 23.3, 375-98.

McNeill, David. 1992. Hand and mind: What gestures reveal about thought, Both. Chicago, IL: University of Chicago Press.

Metzger, Melanie. 1995. Constructed dialogue and constructed action in American Sign Language. In Ceil Lucas (ed.), Sociolinguistics in Deaf Communities, Sign, 255-71. Washington, DC: Gallaudet University Press.

Morgan, Gary. 2002. Children's Encoding of Simultaneity in British Sign Language Narratives. Sign Language \& Linguistics 5.2, 131-65.

Morgan, Gary \& Bencie Woll. 2003. The development of reference switching encoded through body classifiers in British Sign Language. In Karen Emmorey (ed.), Perspectives on classifier constructions in sign languages, Sign, 297-310. Mahwah, NJ: Lawrence Erlbaum Associates.

Neidle, Carol, Judy Kegl, Dawn MacLaughlin, Ben Bahan \& Robert Lee. 2000. The Syntax of American Sign Language, Sign. Cambridge, MA: MIT Press.

Padden, Carol A. 1986. Verbs and role shifting in American Sign Language. In Carol Padden (ed.), Proceedings of the Fourth National Symposium on Sign Language Research and Teaching, Sign, 44-57. Silver Spring, MD: NAD.

Padden, Carol A. 1990. The relation between space and grammar in ASL verb morphology. In Ceil Lucas (ed.), Sign Language Research: Theoretical Issues, Sign, 118-32. Washington, DC: Gallaudet University Press.

Pfau, Roland \& Josep Quer. 2010. Nonmanuals: Their grammatical and prosodic roles. In Diane Brentari (ed.), Sign Languages. Cambridge: Cambridge University Press.

Pfau, Roland \& Markus Steinbach. 2006. Modality-independent and modality-specific aspects of grammaticalization in sign languages. Linguistics in Potsdam 24, 5 98. 
Poulin, Christine. 1994. Null arguments and referential shift in American Sign Language. MIT Working Papers in Linguistics 23, 267-81.

Poulin, Christine \& Christopher Miller. 1995. On narrative discourse and point of view in Quebec Sign Language. In Karen Emmorey \& Judy Reilley (eds.), Language and gesture, 117-31. Mahwah, NJ: Lawrence Erlbaum Associates.

Pyers, Jennie E. \& Ann Senghas. 2007. Reported action in Nicaraguan and American Sign Languages: Emerging versus established systems. In Pamela M. Perniss, Roland Pfau \& Markus Steinbach (eds.), Visible Variation: Comparative Studies on Sign Language Structure, Sign, 279-302. Berlin: Mouton de Gruyter.

Quer, Josep. 2005. Context shift and indexical variables in sign languages. In E. Georgala \& J. Howell (eds.), Proceedings from Semantics and Linguistic Theory 15, Sign, 152-68. Ithaca, NY: CLC.

Quer, Josep. 2011. Reporting and Quoting in Signed Discourse. In E. Brendel, J. Meibauer \& M. Steinbach (eds.), Understanding Quotation, 277-302. Berlin: Mouton de Gruyter.

Quinto-Pozos, David. 2005. Factors that influence the acquisition of ASL for interpreting students. In Marc Marschark, Rico Peterson \& Elizabeth Winston (eds.), Sign Language Interpreting and Interpreter Education: Directions for Research and Practice. Oxford: Oxford University Press.

Quinto-Pozos, David. 2007. Can constructed action be considered obligatory? Lingua $117,1285-314$.

Quinto-Pozos, David, Kearsy Cormier \& Claire Ramsey. 2009. Constructed action of highly animate referents: Evidence from American, British and Mexican Sign Languages. Paper presented at 35th Annual Meeting of the Berkeley Linguistics Society (Special Session on Non-Speech Modalities), Berkeley, CA.

Quinto-Pozos, David \& Sarika Mehta. 2010. Register variation in mimetic gestural complements to signed language. Journal of Pragmatics 42, 557-84.

Reilly, Judy. 2000. Bringing affective expression into the service of language: Acquiring perspective marking in narratives. In Karen Emmorey \& Harlan Lane (eds.), The Signs of Language Revisited: An Anthology to Honor Ursula Bellugi and Edward Klima, Sign, 415-33. Mahwah, NJ: Lawrence Erlbaum Associates.

Sandler, Wendy \& Diane Lillo-Martin. 2006. Sign language and linguistic universals. Cambridge: Cambridge University Press.

Schembri, Adam. 2003. Rethinking "classifiers" in signed languages. In Karen Emmorey (ed.), Perspectives on Classifier Constructions in Sign Languages, Sign, 3-34. Mahwah, NJ: Lawrence Erlbaum Associates.

Schick, Brenda S. 1987. The Acquisition of Classifier Predicates in American Sign Language. $\mathrm{PhD}$ dissertation dissertation, Purdue University.

Schlenker, Phillipe. in press. Super Monsters 1: Attitude and Action Role Shift in Sign Language. http://ling.auf.net/lingbuzz/002069. Semantics and Pragmatics,

Slobin, Dan, Nini Hoiting, Marlon Kuntze, Reyna Lindert, Amy Weinberg, Jennie Pyers, ... Helen Thurmann. 2003. A cognitive/functional perspective on the acquisition of "classifiers". In Karen Emmorey (ed.), Perspectives on classifier constructions in sign languages, 271-296 edn, Sign. Mahwah, NJ: Lawrence Erlbaum Associates. 
Supalla, Ted. 1982. Structure and Acquisition of Verbs of Motion and Location in American Sign Language. $\mathrm{PhD}$ dissertation dissertation, University of California at San Diego.

Supalla, Ted. 2003. Revisiting visual analogy in ASL classifier predicates. In Karen Emmorey (ed.), Perspectives on classifier constructions in sign languages, 249-57. Mahwah, NJ:

Tannen, Deborah. 1986. That's Not What I Meant!: How Conversational Style Makes or Breaks Your Relations with Others. New York: William Morrow.

Tannen, Deborah. 1989a. Interpreting Interruption in Conversation. In Bradley Music, Randolph Graczyk \& Caroline Wiltshire (eds.), ClS 25: Papers from the 25th Annual Regional $n$ Meeting of the Chicago Linguistic Society; Part Two: Parasession on Language in Context. Chicago, IL: Chicago linguistic Society.

Tannen, Deborah. 1989b. Talking voices: Repetition, dialogue, and imagery in conversational discourse. Cambridge: Cambridge University Press.

Thompson, Robin. 2006. Eye gaze in American Sign Language: Linguistic functions for verbs and pronouns. $\mathrm{PhD}$ diss. dissertation, University of California, San Diego.

Thompson, Robin, Karen Emmorey \& Robert Kluender. 2006. The relationship between eye gaze and verb agreement in American Sign Language: An eyetracking study. Natural Language and Linguistic Theory 24.2, 571-604.

Thompson, Robin, Karen Emmorey \& Robert Kluender. 2009. Learning to look: The acquisition of eye gaze agreement during the production of ASL verbs. Bilingualism: Language and Cognition 12.4, 393-409.

Wilcox, Sherman. 2009. Symbol and symptom: Routes from gesture to signed language. Annual Review of Cognitive Linguistics 7, 89-110.

Winston, E. 1992. Space and involvement in an American Sign Language lecture. In J. Plant-Moeller (ed.), Expanding Horizons: Proceedings of the Twelfth National Convention of the Registry of Interpreters for the Deaf, 93 - 105. Silver Spring, MD: RID Publications.

Zimmer, June. 1989. Toward a description of register variation in American Sign Language. In Ceil Lucas (ed.), The sociolinguistics of the deaf community, Sign. San Diego: Academic Press.

Zwitserlood, Inge. 2003. Classifying Hand Configurations in Nederlandse Gebarentaal (Sign Language of the Netherlands). Utrecht University: LOT.

\section{Author contact information}

Kearsy Cormier

Deafness, Cognition and Language Research Centre

University College London

49 Gordon Square

London WC1H 0PD

UK

Tel: +44 (0)2076798674

Email:k.cormier@ucl.ac.uk

\section{Acknowledgements}

We thank Fanny Limousin, Ramas Rentelis, and Katherine Rowley for assistance in coding the data presented here. We also thank Jordan Fenlon and Martine Zwets and 
two anonymous reviewers for comments on earlier drafts of this paper. Support for this research was provided by the Arts and Humanities Research Council of Great Britain (Grant 119360), the Economic and Social Research Council of Great Britain (Grants RES-620-28-6001 and RES-620-28-6002), Deafness, Cognition and Language Research Centre (DCAL).

\footnotetext{
${ }^{1}$ Note however that we also adopt the use of terminology of other researchers who we think are talking about the same or related phenomena, when talking about their work. 2 "Classifier constructions" are another phenomenon in sign languages which have often been not clearly defined - see Schembri (2003).

${ }^{3}$ Examples (1) - (3) are reproduced from Metzger (1995) as closely as possible. It is not clear which of her glosses are intended to represent lexical signs or classifier constructions or simply any meaningful manual activity which for example might include manual constructed action (though presumably since some classifier constructions are marked as "CL:", this would suggest that the other glosses are not classifier constructions).

${ }^{4}$ Such mechanisms have been considered to be grammatical markers of the signer's shift into the role of a character, conveying information from that character's perspective. For a review, see Lillo-Martin (2012).

5 It is not clear where Engberg-Pedersen's (1993) 'shifted locus' fits into Table 1.

${ }^{6}$ A real-space blend for Dudis (2004), also known as a surrogate blend (Liddell 2003) is the mental process by which signers conceptually map a referent onto large-scale space.

${ }^{7}$ We should note that it can be difficult to distinguish some of these other functions of the mouth (e.g. morphological mouth gestures such as ' $\mathrm{mm}$ ' to mean that an action is done without effort) from enactment (CA) of the mouth. It is likely that these difficulties arise because of grammaticalisation processes that relate affective facial expressions to such grammatical markers (Pfau \& Steinbach 2006, Wilcox 2009, Johnston, van Roekel \& Schembri 2015).

${ }^{8}$ Because it is possible for signers to represent more than two referents using constructed action via body partitioning where different articulators represent different referents (Dudis 2004), we did have tiers available for Role3 and Role4. For these narratives, none of our participants ever produced CA representing more than two roles at a time.

${ }^{9}$ Note that these developmental trajectories are what we would predict in language acquisition, and these provide some models that can be tested with child acquisition data (possibly also in L2 acquisition in adult learners and in clinical populations; Quinto-Pozos et al. 2013). However we are making no claims about historical trajectories or grammaticalisation, or degree to which any of these are linguistic or gestural. Given what has been found in previous research comparing CA in deaf signers and hearing non-signers (e.g. Earis \& Cormier, 2013), we would predict the same kinds of trajectories in non-signers. We leave this for future research.
} 